$$
\text { DOE/PC/90177 N T }
$$

$\mathrm{DOE} / \mathrm{PC} / 90177--\mathrm{T} 5$

DE92 005197

\title{
EVALUATION, ENGINEERING AND DEVELOPMENT OF ADVANCED CYCLONE PROCESSES
}

QUARTERLY TECHNICAL PROGRESS REPORT

Quarterly report \# 04

for the period July I, 1991 to september 30, 1991

Work Performed Under DOE Contract \# DE-AC22-90PC90177

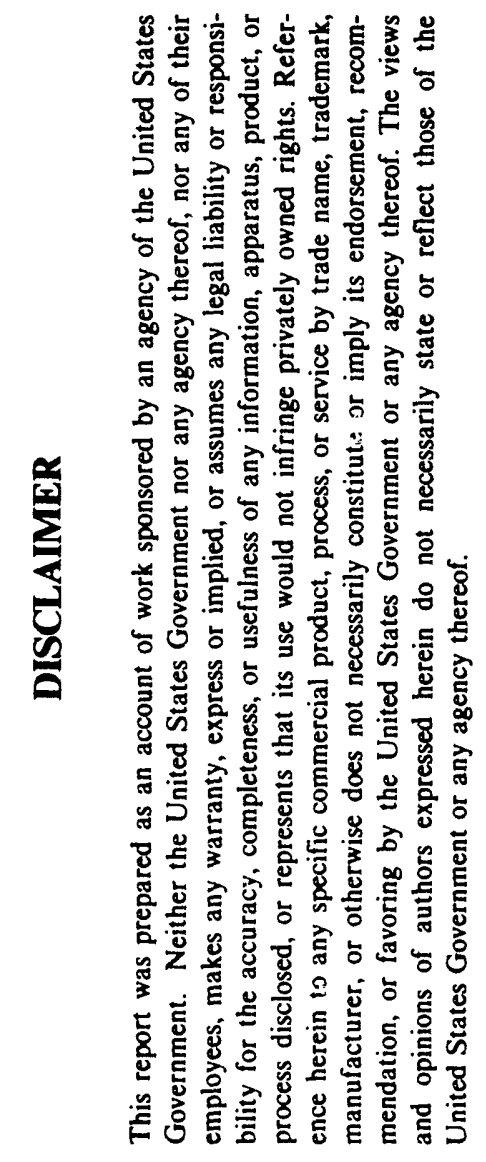

For

U.S. Department of Energy

Office of Fossil Energy

Pittsburgh Energy Technology Center

P.O. Box 10940

Pittsbirgh, PA 15236

By

Coal Technology corporation

103 Thomas Road

Bristol, VA 24201 



\section{EXECUTIVE SUMMARY}

The project's goal is to develop an advanced coal beneficiation technology that can achieve high recovery of the parent coal's calorific value, while maximizing pyritic sulfur removal. Coal cleaning is to be accomplished by physical means and incorporate an advanced form of cycloning, or multiple gravity process. Evaluation of different media types and their attendant recovery, concentration, and regeneration systems is to be completed. Phase I, now completed, involved a paper study and a number of laboratory tests to eliminate unfeasible options. Phase II involves detailed testing of the more promising media and separators in a closed loop circuit. The separatory devices under consideration for Phase II include small diameter high pressure cyclones, a centrifuge, and a magnetically enhanced media (MEM) separator or another option. The third phase and final phase, Phase III, will test a 1,000 1b/hr open loop, benchscale plant designed with the optimum media, separator, and media recovery process based on information gathered during the course of the project.

This fourth quarter was spent completing the media evaluation, working on the coal characterization, obtaining information on media recovery equipment, and readying for phase II. The feed coal coarse washabilities have been completed and the fine nearly so. Complete washability for the Illinois No. 6 coal is presented in this report. Washing, and separation tests with dispersants have been conducted on the successful media. A large body of data has been collected concerning the media evaluation. The project team is recommending that MCL/perc, and calcium nitrate be used during Phase II, Media Testing.

It is becoming clear that the MEM separator, under development for the past two quarters, will be replaced by Hydroprocessing's Centrifloat separatory device for consideration in Phase II. Centrifloat appears to be more of a viable option than the MEM separator that has experienced problems in development. A technical obstacle exists in developing a high throughput, hydraulically powered separator to work with the Magnetically Enhanced Media. The problem is not with the media or with the separator but rather in marrying the flow profile to the magnetic force profile of the permanent magnet. Arrangements were made with Hydroprocessing to perform some initial tests so the project team could evaluate their process and possibly provide an alternative for the failing MEM separator. This test work has been completed but the analysis has not. If the Centrifloat fails, then it too is practically eliminated from Phase II. 
Accomplishments this quarterly reporting period include:

- Medias for Phase II have been selected

- Washing tests with dispersants have been completed

- Separation tests with dispersants have been completed

- Washability analysis is nearly complete

- A Phase II test matrix has been developed 


\section{INTRODUCTION}

"Evaluation, Engineering and Development of Advanced Cyclone Processes" is a research and development project for the reduction of pyritic sulfur in coal. Project goals are to remove 80 to $90 \%$ of the ash and pyritic sulfur while retaining 80 to $90 \%$ of the parent coal's heating value. A number of media and media separator options are to be evaluated and tested, culminating with the implementation of the preferred combination in a 1,000 lb/hr bench-scale process optimization circuit.

The project involves the physical beneficiation of coal and is based on the density differential that exists between clean coal, and its impurities - pyrite and ash bearing minerals. Coal may be beneficiated by employing a parting liquid that possesses or behaves as a liquid with a density between that of coal and its impurities. A number of parting liquids or separating media are under consideration for evaluation and testing in this program. Among these are families of liquids, including: aqueous solutions, organic liquids, and aqueous suspensions. The aqueous suspensions of starch and solutions of sugar, though environmentally benign, were dropped from consideration early in the program for their high viscosity and handling difficulties. Micronized magnetite, an aqueous suspension, was also dropped because another firm intends to develop its manufacture and use to the point of commercialization. Except for the aqueous suspensions the candidate media may be classified as true heavy liquids. True heavy liquids have the benefit of not being affected by the multiple gravities usually employed in fine coal gravimetric processes, whereas suspensions may deteriorate if too great a force is exerted upon them. Multiple gravities can be used to speed the separation, increase efficiency, and allow particles with even slight differences in specific gravity to be separated. Generally, the greater the number of gravities the more precise the separation. This implies the use of small diameter, high pressure inlet cyclones or high gravity separatory centrifuges. The term cycloning here refers to centrifuges and other enhanced gravity devices where fluid motion or mechanical motion is converted into centrifugal force.

IGC is developing a Dynawhirpool and elongated cylindrical section cyclone to perform as separators using the MEM. These separatory devices are thought to be easily adaptable to the fluid and use a permanent magnet. IGC already has a very capable laboratory scale separator the largest practical one has a capacity of $100 \mathrm{lb} / \mathrm{hr}$ termed the 1000E. This device costs $\$ 135,000$ and is not viewed as economically feasible for this project's budget or in terms of commercial plant. The dynawhirpool and cyclone are thought to be economically attractive alternatives to the Magstream 1000E, which uses the same principles but centrifugal force is provided by a mechanically driven rotor not unlike in a centrifuge. In the Dynawhirpool and the cyclone the centrifugal force are provided by hydraulic fluid motion produced from pumping. 
Task 1 - Project Plannirig \& Management

Task Description or objective(s): The objective of this task is good technical and fiscal control and direction of this project both internally and externally through communication with coal Technology corporation (CTC) as prime contractor and through CTC with the Department of Energy. CTC will be responsible for interfacing with the DOE and ensuring that all subcontractors are fulfilling their responsibilities and meeting the milestones and goals of the project work plan. The subcontractors are:

Process Technology Corporation (PTI) - Subcontractor
providing analytical services and conducting Phase I
and II laboratory and closed-loop media testing.
ICF Kaiser Engineers, Incorporated (ICF KE) -
Subcontractor performing detailed design and overseeing
construction of bench-scale circuit, along with $3 \mathrm{TPH}$
POC circuit conceptual design.
Intermagnecics General corporation (IGC) -
- Subcontractor providing media, separator, and technical
service for magneticaliy enhanced media.

A significant amount of effort was concentrated near the beginning in submitting the Project Work Plan and QA/QC Plan. Project management is an ongoing effort designed to monitor the subcontractors, keep the project running smoothly, resolve conflicts, and in general ensure that the project is performed on a timely and cost effective basis. Project duration is 30 months, though an extension to 35 months is contemplated.

Activity: The Project Work and $\mathrm{QA} / \mathrm{QC}$, Manpower and cost Plans, and the Milestone Schedule were submitted, revised, and approved.

\section{Task 2 - Coal Procurement and Characterization (Three Phases)}

Task Description or objective(s): The objective of this task is to provide characterized feedstock for all three phases of the program. The three phases are associated with: (I) separating Media Evaluation, (II) Separating Media Testing and, (III) Process optimization Testing. A total of four coals have been designated for the program. The four coals constitute a substantial reserve, are a technical challenge to clean and contain significant amounts of pyritic sultur. The

characterization will determine the amount of liberation needed to obtain the desired depth of cleaning. This information will be used as a data base for the entire program and to measure the performance of individual tests. 
The project's requirements for the four coals include:

- Raw coals must have moderate to high pyritic sulfur contents where pyrite is not sufficiently liberated at the coarse sizes used in conventional cleaning

- Precleaning operations must recover $90 \%-95 \%$ of the parent raw coal's heating value, while principally removing coarse rock and fine clays

Raw and clean coal handling systems must facilitate readily obtaining one-to-two ton samples of the raw and precleaned coals for the Phase I and Phase III coal characterization

Activity: Head analysis and coarse washabilities for the four coals were presented in the Quarterly Report \#03. Fine washabilities (28M $\%$ o) remain to be completed for several of the coals, but the entire washability analysis for the Illinois No. 6 coal is complete and presented here. The data is presented in Appendix A. Ash, sulfur, and pyritic sulfur relationships are plotted in Figures 1 through 6. The following comments may be made about the comparison of the $3 / 4$ to $400 \mathrm{M}$ washabilities.

Ash versus recovery relationships

Figures 1 and 2 contain a comparison of the cumulative ash versus yield and energy recovery washability relationships for the 3/4-inch to 400M topsize grinds. Improved liberation of ash can be observed for finer grinds, by the fact that it is higher and to the left. The improvements are also enhanced for energy recovery curves relative to the yield curves. Comparison of those curves allows one to quantify the extent of liberation improvements at progressively finer topsizes.

\section{Sulfur versus recovery relationships}

similar plots comparing the sulfur versus yield and energy recovery washability relationships for the $3 / 4$-inch to $400 \mathrm{M}$ topsize grinds for the Illinois No. 6 seam Precleaned Coal are contained in Figures 3 and 4 . For grinds finer than 100M, the sulfur content initially drops upon going to higher gravities above 1.30. This is due to the fact that the float 1.30 coal macerals have a higher organic sulfur content than the 1.30 to $1.50 \mathrm{SG}$ coal macerals (see Appendix A) which causes an initial drop on going to cumulative higher gravities. As inorganic sulfur content (pyritic sulfur) begins to increase in the extremely high gravities ( 1.50 to 1.80$)$, the overall sulfur finally begins to increase. As with the ash versus recovery relationships, the overall sulfur liberation is improved slightly upon going to finer grinds. 
Figure 1

ASH VERSUS YIELD WASHABILITY RELATIONSHIP

3/4-INCH, 28M, 100M, 200M, AND 400M TOPSIZE GRINDS

(Illinois No. 6 Seam Precleaned Coal)

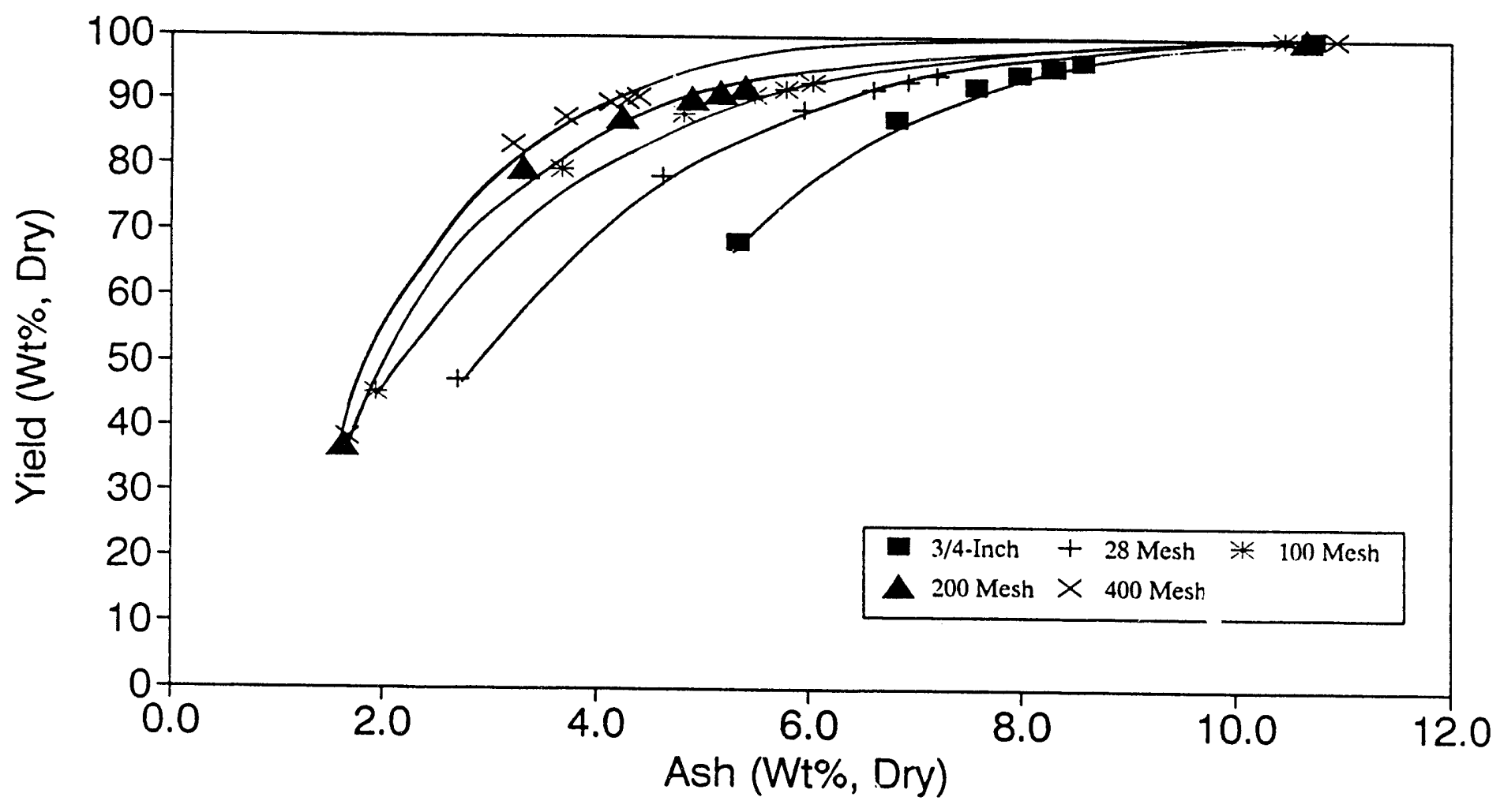




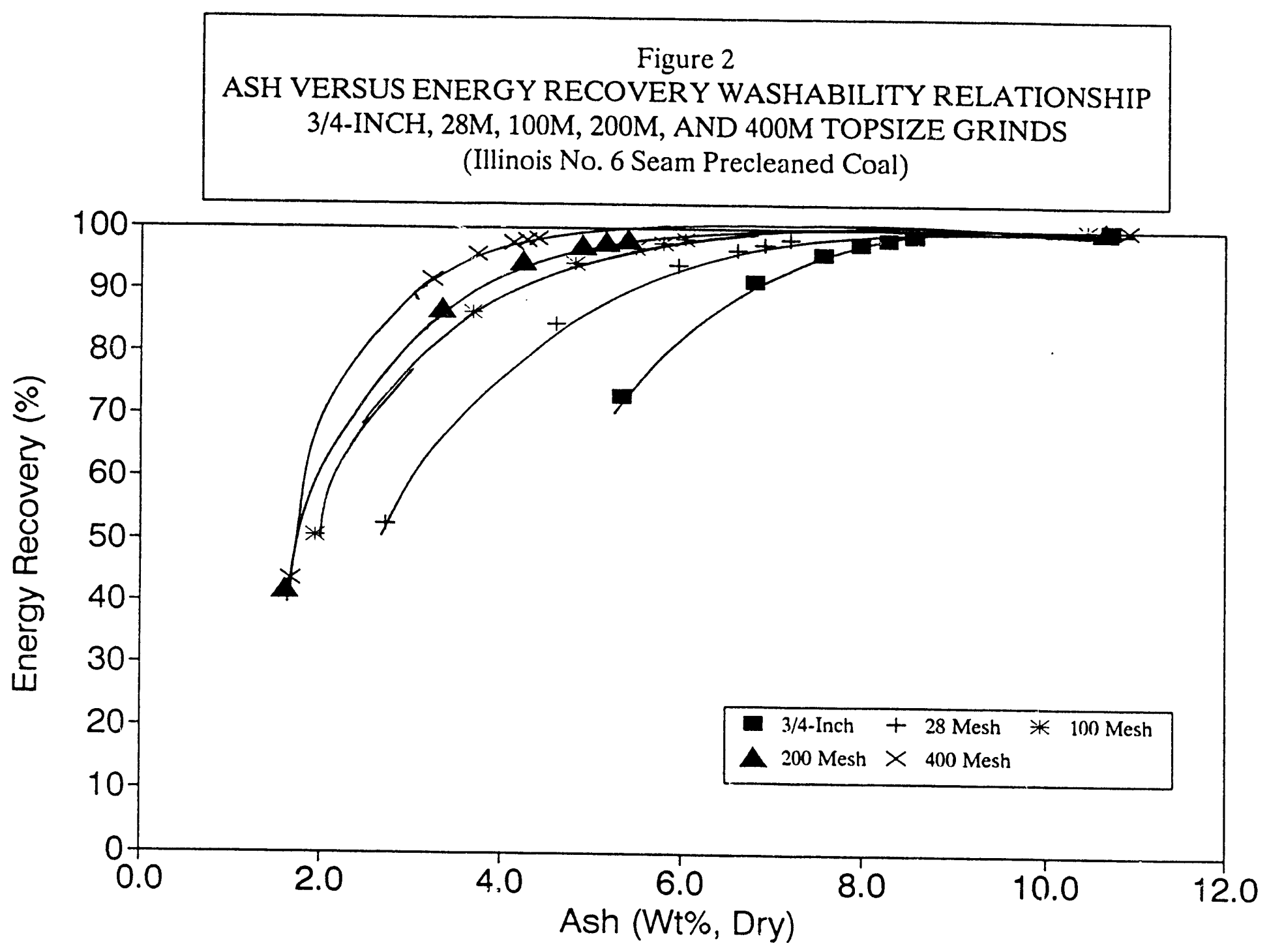




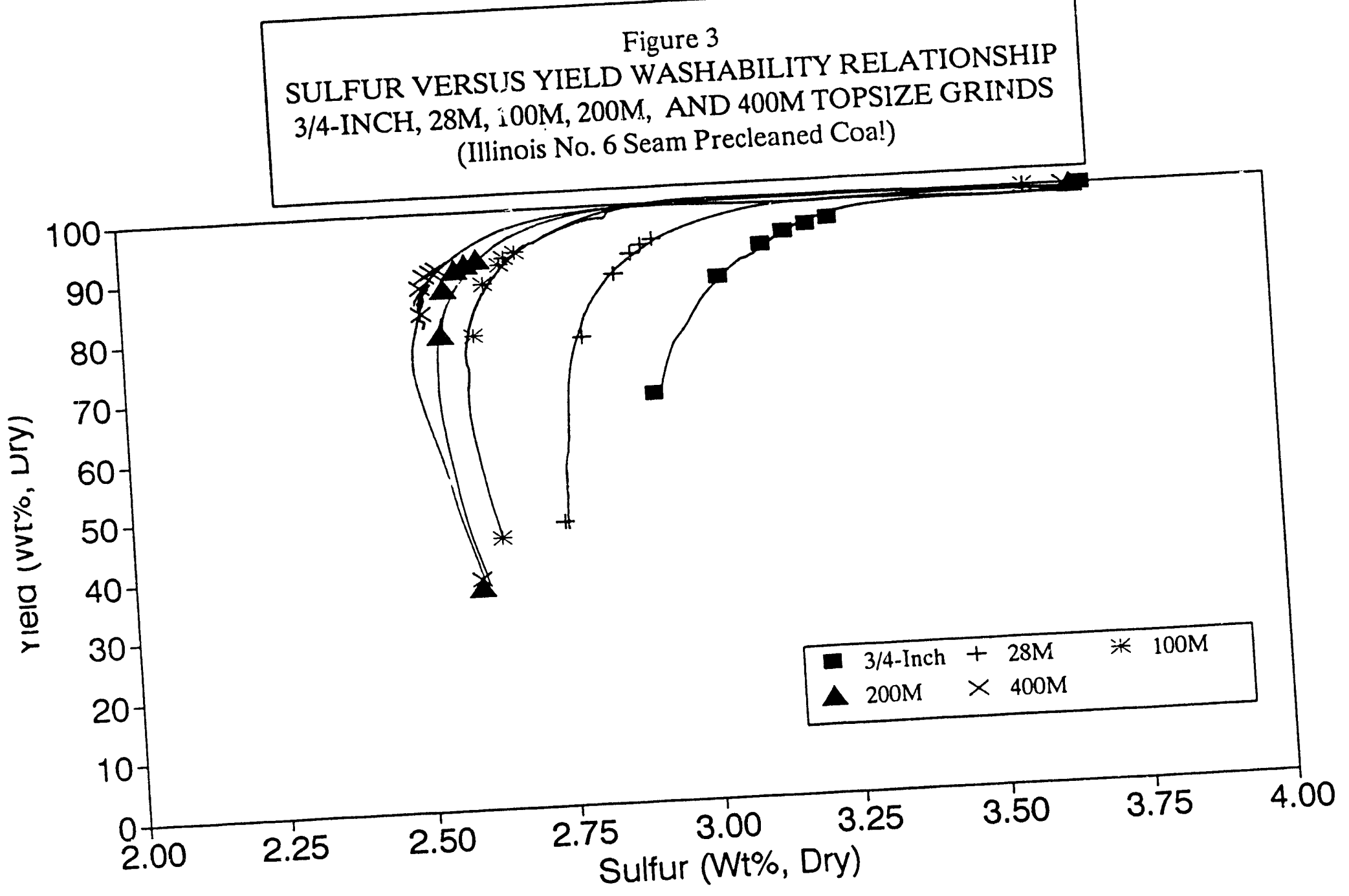


Figure 4

SULFUR VERSUS ENERGY RECOVERY WASHABILITY RELATIONSHIP 3/4-INCH, 28M, 100M, 200M, AND 400M TOPSIZE GRINDS

(Illinois No. 6 Seam Precleaned Coal)

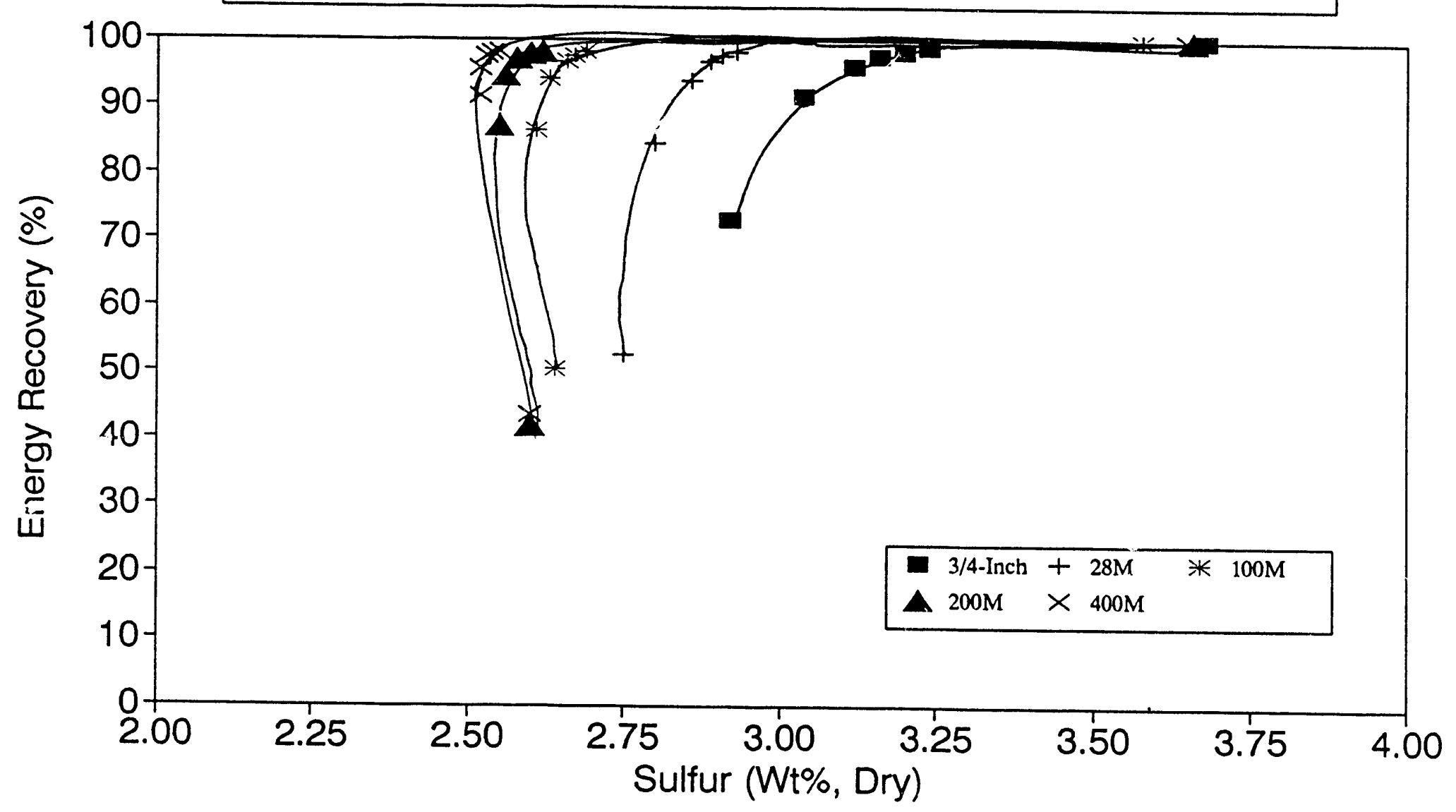


Figure 5

PYRITIC SULFUR VERSUS YIELD WASHABILITY RELATIONSHIP

3/4-INCH, 28M, 100M, 200, AND 400M TOPSIZE GRINDS

(Illinois No. 6 Seam Precleaned Coal)

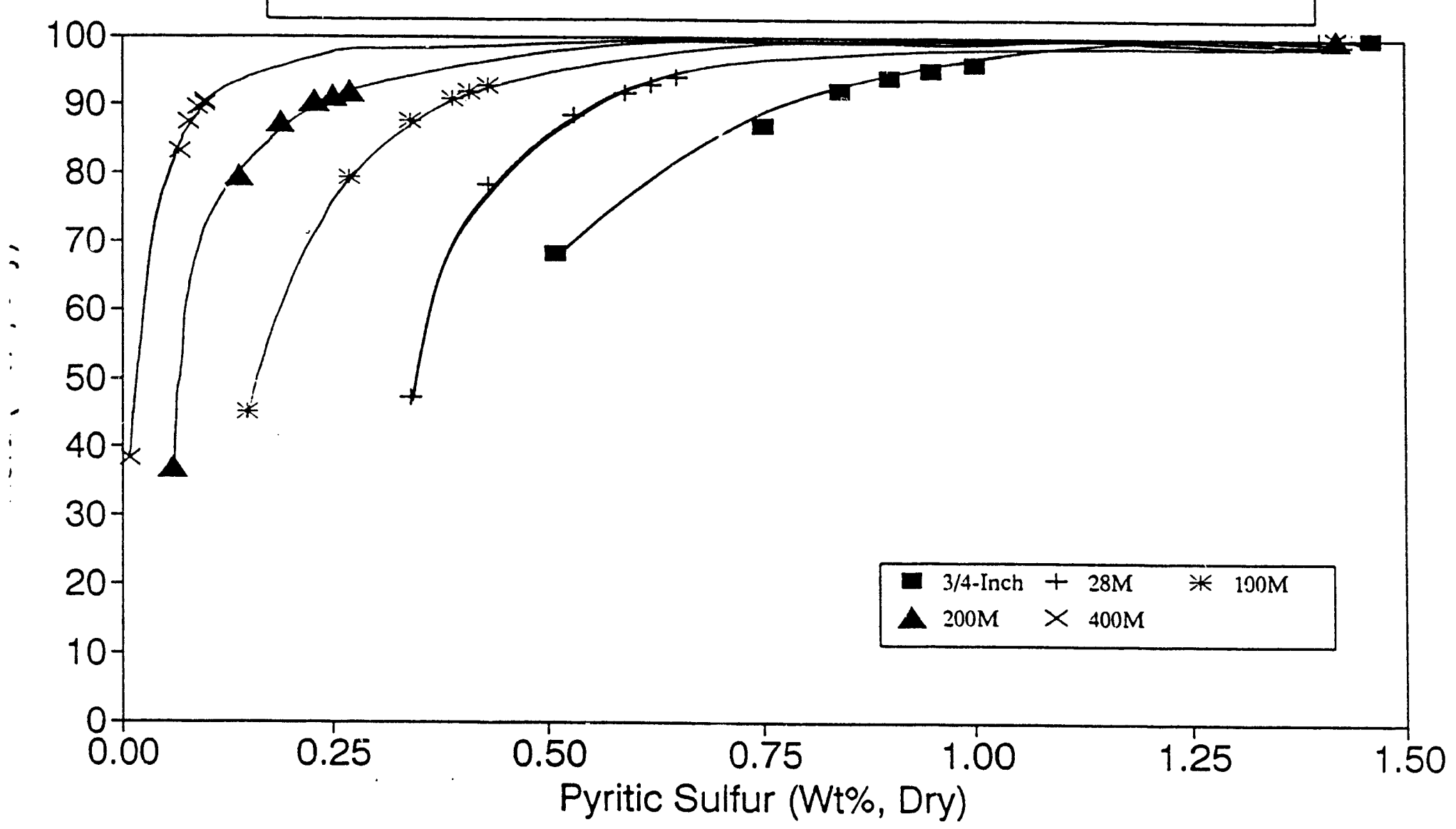


Figure 6

PYRITIC SULFUR VERSUS ENERGY RECOVERY WASHABILITY RELATIONSHIP 3/4-INCH, 28M, 100M, 200M, AND 400M TOPSIZE GRINDS

(Illinois No. 6 Seam Precleaned Coal)

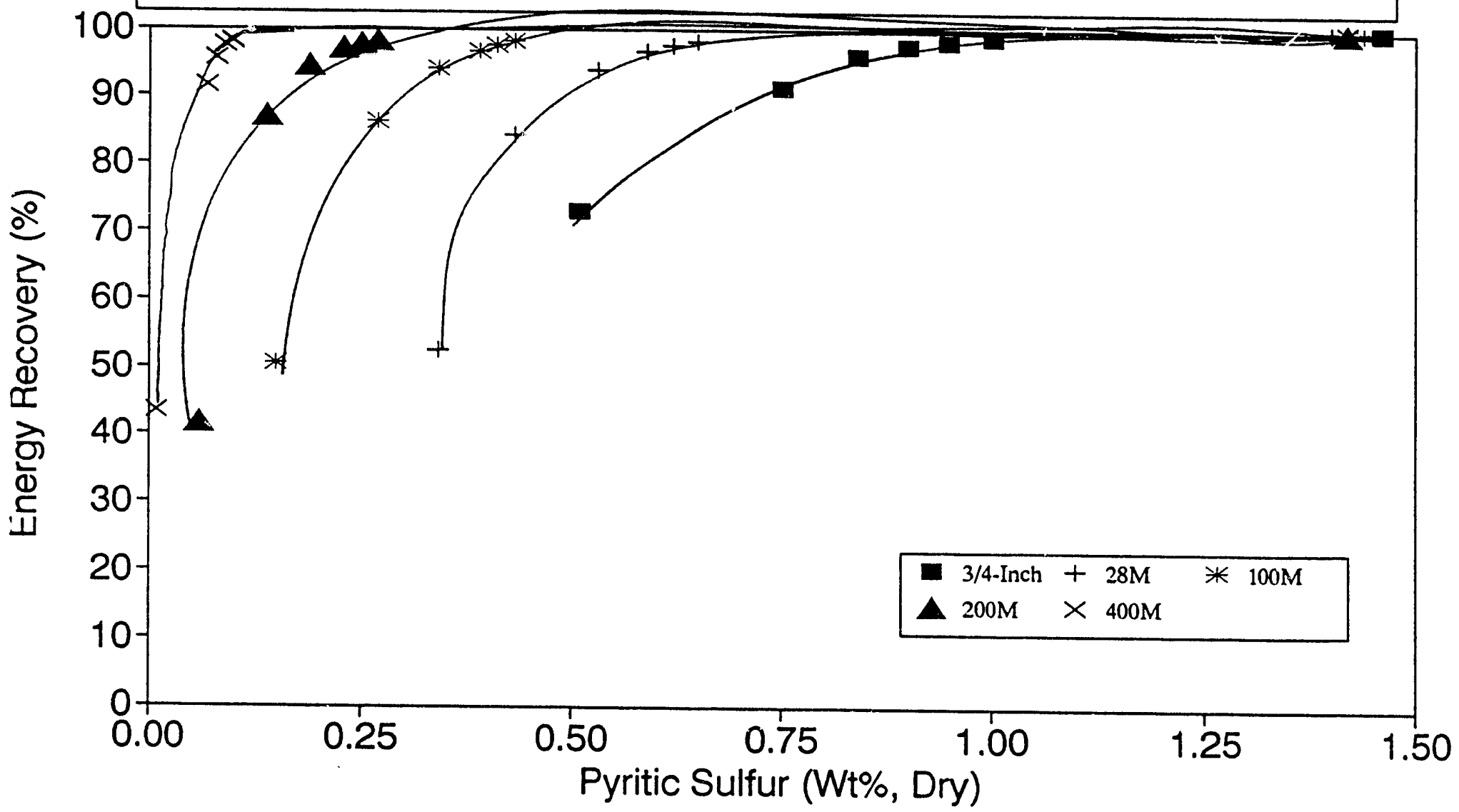


Pyritic sulfur versus recovery relationships

The last set of curves (shown in Figures 5 and 6) contain a comparison of the pyritic sulfur versus yield and energy recovery washability relationships for the $3 / 4$-inch to $400 \mathrm{M}$ topsize grinds. These curves illustrate that pyritic sulfur liberation improves dramatically with finer grinding. However, keep in mind that despite this dramatic improvement in pyritic sulfur content removal potential for the finer grinds, the improvements in total sulfur content are likely to be much less significant as shown in Figures 3 and 4 , particularly when the increased difficulty of separating the finer $400 \mathrm{M} \times 0$ feed coal in a continuous plant application (i.e. conventional cycloning) is considered.

One interesting aspect of the fine washability is that the $400 \mathrm{M} \times 0$ was performed using cesium chloride as the parting liquid. This medium and the procedure using it are without question superior for ve. I fine coal as compared to prior methods as shown by the uniformity and consistent trend toward the upper left corner. The final Washability Analysis Report including Microtrac size analysis, contact angle measurements, zeta potential, pyrite grain size observations, and washability relationships for yield, and energy recovery vs ash, sulfur and pyritic sulfur for the remaining three coals is expected to be ready by the end of occober.

The Phase II test coal, Illinois No. 6, was collected under PTI's supervision at ARCH Mineral's Captain Mine and shipped to collected. Only one coal will be used during Phase II.

\section{Task 3 - Evaluation Plan and Test Plan Formulation}

Task Description or Objective(s): Task 3 represents the planning stage of the work that will be conducted during Phase I through III of Task 6. It is the technical basis of the program and provides for evaluating the media by paper study supplemented by laboratory study, selection of medium and separator combination and finaliy implementation of one medium separator option for long term open loop testing. The three phases of this task are:

- Separating Media Evaluation Plan

- Separating Media Testing Plan

- Process optimization Test Plan

These plans detail the Task 6 scope of Work.

Activity: The Separating Media Evaluation Plan was approved by DOE in early February 1991. The Separating Media Test Plan (Phase II) was submitted in draft form in late september with the 
Preliminary Separating Media Evaluation Report, and is reproduced here under Task 6 discussion.

\section{Task 4 - Bench-Scale Test Circuit Design}

Task Description or Objective(s): This task involves the design of a fully integrated bench-scale advanced cycloning test circuit. The design of the advanced cycloning test circuit will be based on the separating Media Evaluation and Testi.ng results (Phase I and II) and the detailed characterization of the four proposed test coals. ICF Kaiser Engineers will be the lead team menber for Task 4. The duration of this task is expected to be four months, and its scope description is contained in the Pruject Work Plan.

The bench-scale advanced cyclone test circuit will be fully integrated and include alj treatment, cleaning and post-cleaning necessary to allow continuous steady-stat? operation including at least one (1) run of 100 hours duration in length for each of the
four coals tested.

Activity: No activity scheduled during this period.

\section{Task 5 - Bench-Scale Test Circuit set-up \& Commissioning}

Task Description or orjective(s): This task covers the functions necessary to install and successfully start-up the bench-scale circuit module at the job site, i.e. inside CTC's existing building located near Bristol, virginia. The installation will be carried out by an installation subcontractor with construction management provided by ICF KE. The start-up will be supervised by CTC and conducted using engineers from ICF KE and craft labor supplied by the installation subcontractor.

Activity: No activity scheduled during this period.

\section{Task 6 - Evaluation \& Test Plan Implementation}

Task Description or objective(s): This task consists of the technical implementation of plans produced and approved under Task 3. Please refer to the project Separating Media Evaluation Plan approved in February 1991.

Activity: Phase I Media Evaluation

The media evaluation was completed during this quarter and reported in the recently submitted draft Preliminary Separating Media Evaluation Report, however, for continuity the main results
are reported here. 
STEP ONE - MEDIA SELECTION AND EVALUATION

Various sources werc used to obtain a list of media to evaluate for candidacy as a parting liquid. Nearly 50 candidates were chosen and then exposed to a decision tree to further examine their suitability. The media that passed the decision tree were scored according to a weighted criteria and the top scoring media were retained for further analysis and inspection.

The 9 media selected at the end of step one of the media evaluation were.

$\begin{array}{ll}\text { Media } & \text { (Formula) } \\ \text { 1- Magnetizally Enhanced Media } & \begin{array}{l}\text { Lignosulfonic Acid } \\ \text { 2- Micronined Magnetite }\end{array} \\ \text { 3- Potassium Carbonate } & \mathrm{Fe}_{3} \mathrm{O}_{4} \\ \text { 4- Calcium Nitrate } & \mathrm{Ca}_{3} \cdot 3 / 2 \mathrm{H}_{2} \mathrm{O} \\ \text { 5- Dipotassium Phosphate } & \left.\mathrm{K}_{2} \mathrm{HPO}_{4}\right)_{2} \\ \text { 6- Calcium Chloride } & \mathrm{CaCl}_{2} \\ \text { 7- Ferric Sulfate } & \mathrm{Fe}_{2}\left(\mathrm{SO}_{4}\right)_{3} \\ \text { 8- MCL/Perc Mixture } & \mathrm{CH}_{2} \mathrm{Cl}_{2} / \mathrm{C}_{2} \mathrm{Cl}_{4} \\ \text { 9- Potassium Phosphate } & \mathrm{K}_{3} \mathrm{PO}_{4}\end{array}$

STEP TWO - LABORATORY STUDY

Part I - Viscosity vs Temperature Tests

These tests measured the viscosity of the various media at three gravities and six temperatures. The tests results also indirectly yielded solubility and cost data which were useful in later evaluations. The results of these tests were reported in Quarterly Report \# 02. At the conclusion of this matrix two media were dropped from consideration. Dipotassium phosphate was dropped because it scored low and was very similar to potassium phosphate, yet more costly. Micronized magnetite was dropped because it was on the verge of commercialization by Custom Coals International.

Part IIA - Primary Test Matrix

This matrix involved measurement of media viscosity with coal loading and the aid of selected dispersants. Viscosity measurements using no dispersant were also performed. Selection of dispersants for each medium was conducted by Dr. Jim Hwang who selected two dispersants for each. Those being: i) the best but not necessarily well known performer, and 2) the best of conventional well known dispersants. Results of this test matrix were reported in quarterly Report \#03.

Part IIB - Laboratory Centrifuge Separation Tests

Table IA shows the complete results for the Initial Separation Tests, tests $1-24$, conducted without dispersants. 


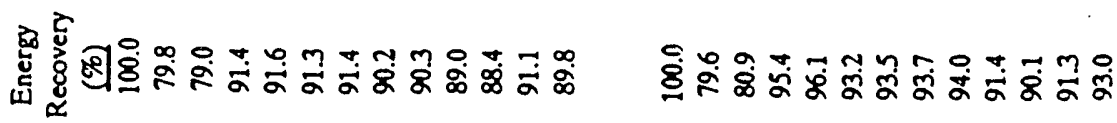

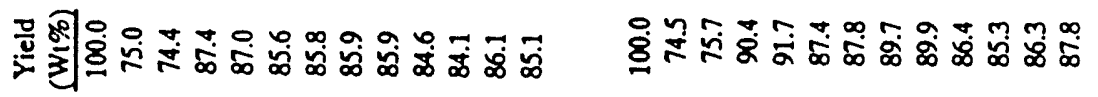
|

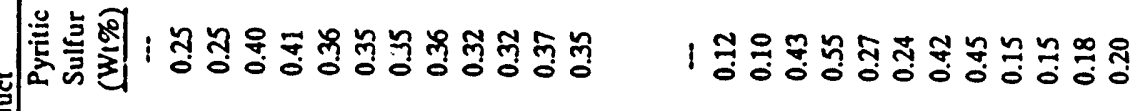

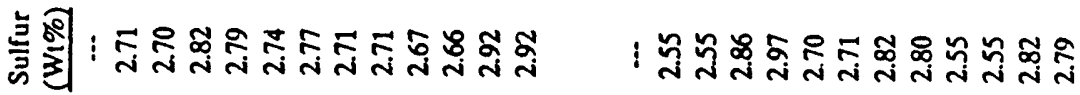

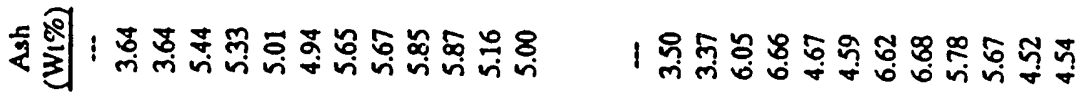

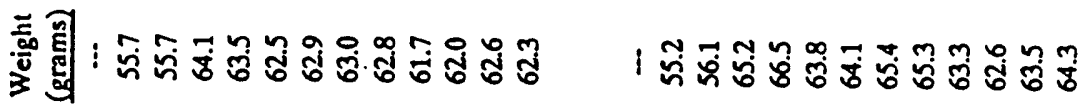

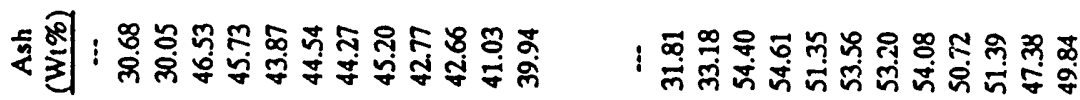

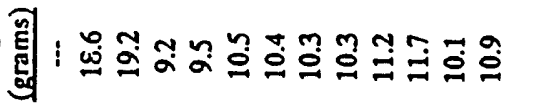

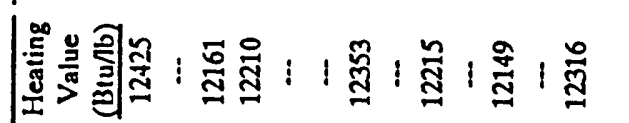

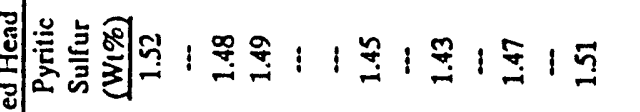

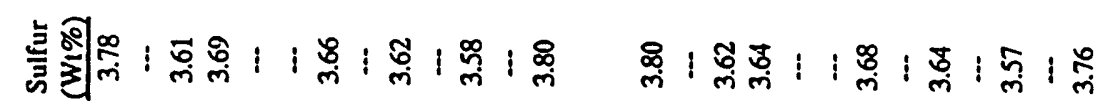

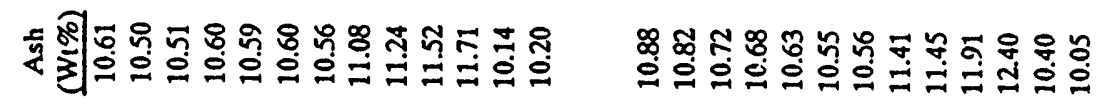

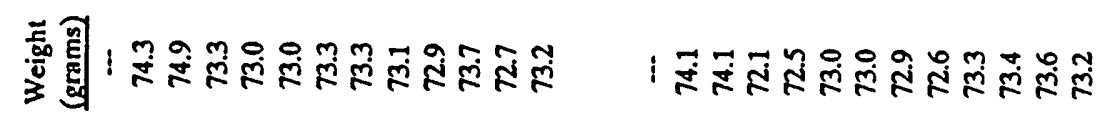

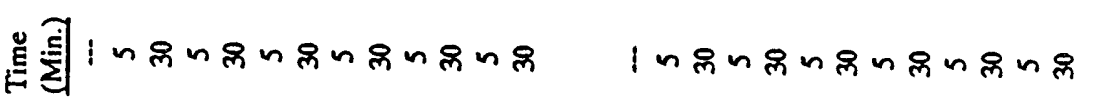

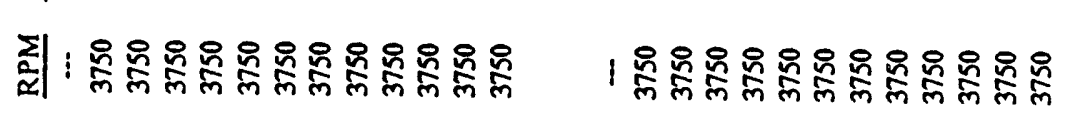
도눌

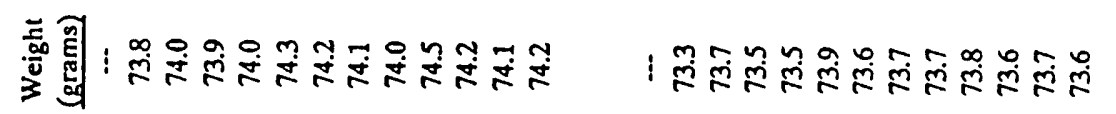

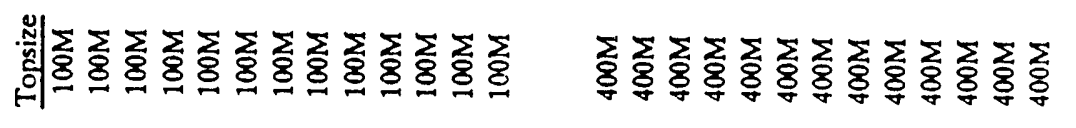

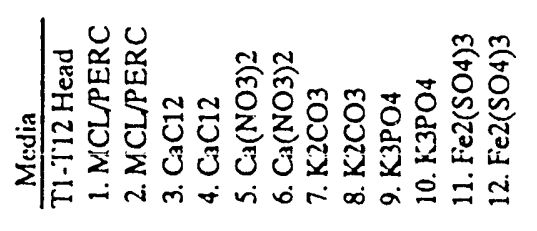

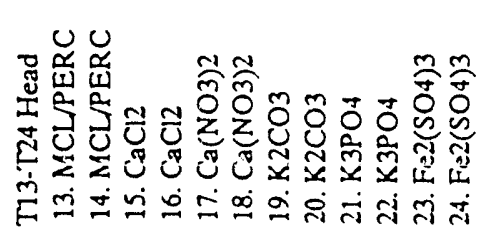

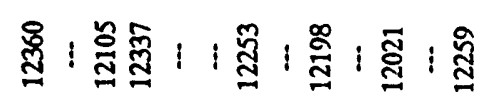

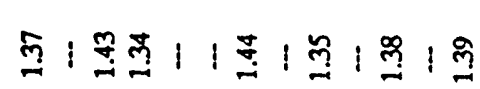

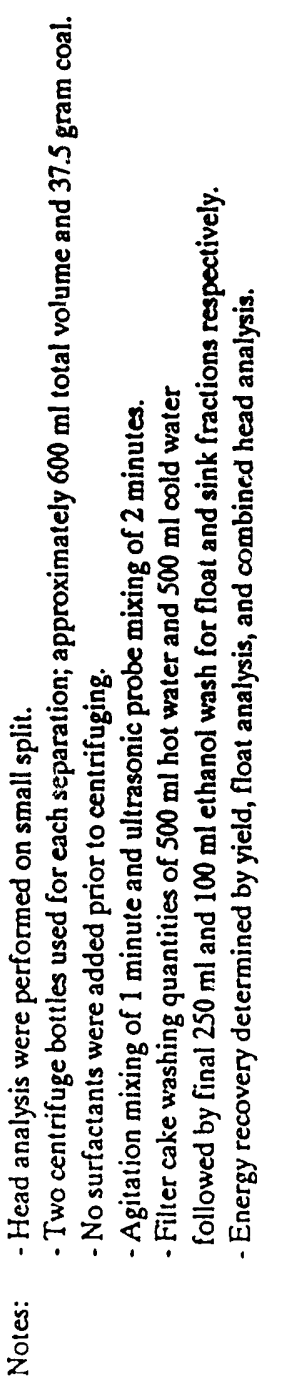




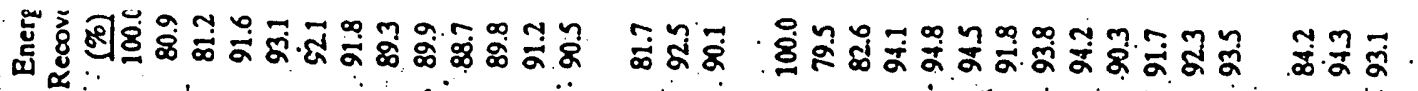

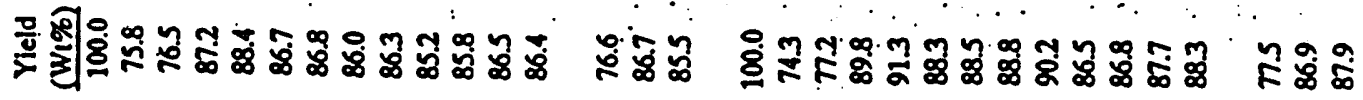

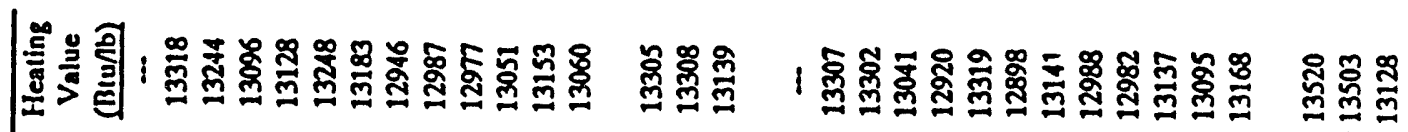

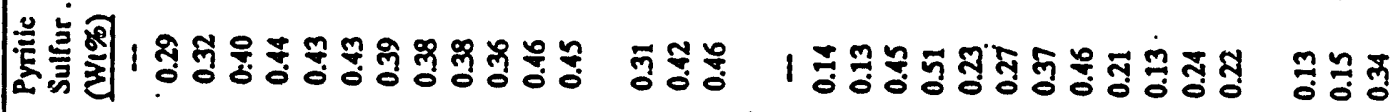

홍

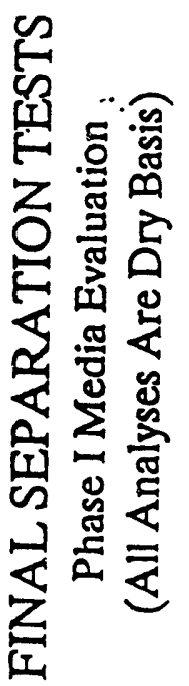

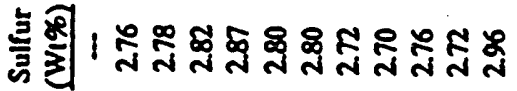

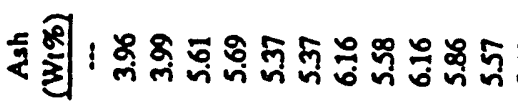

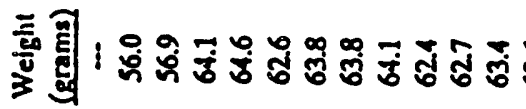

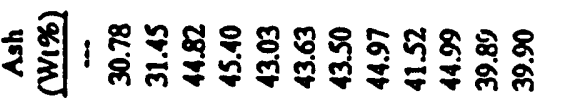

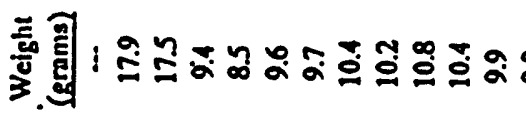

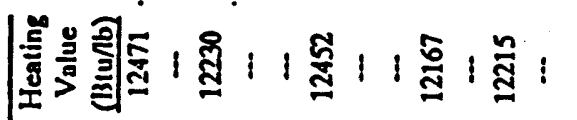

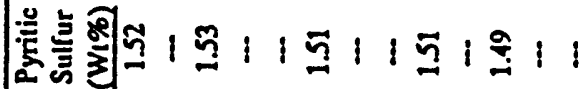

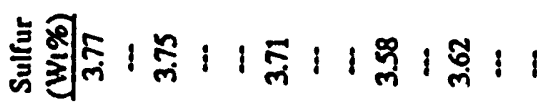

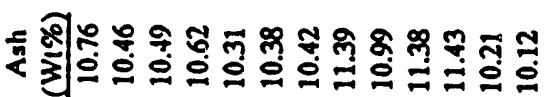

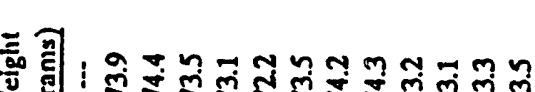

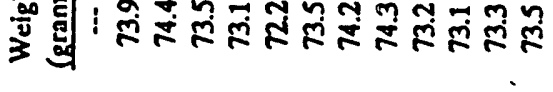

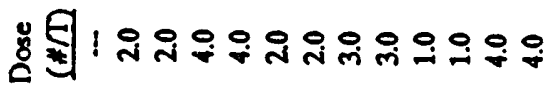

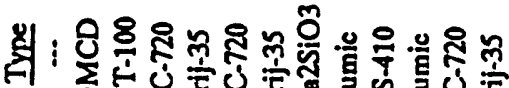

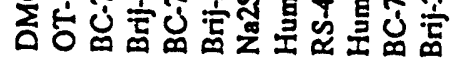

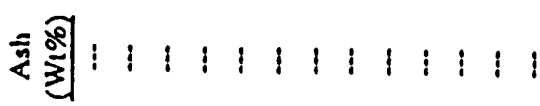

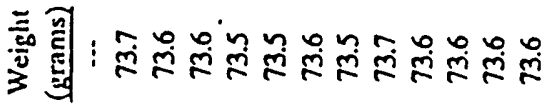

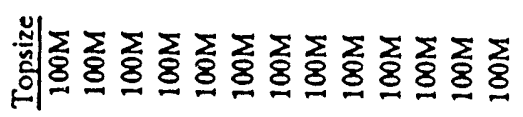

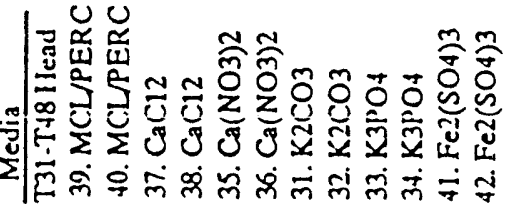

สุลั่

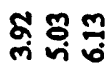

ํํํํำ

$8 \div$

วัะ์

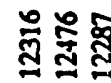

รทฺุั

ت.

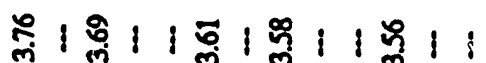

हnं

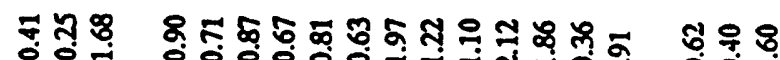

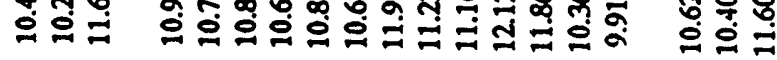

$\min$

|

ลี สำ

웅ํ

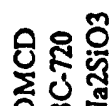

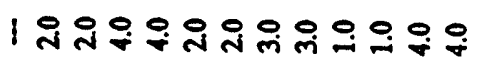

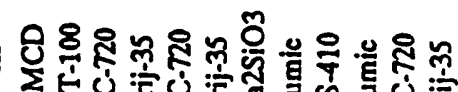

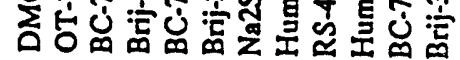

윻융웡

ิㅗํํํำ 㐫瓷元

\section{1}

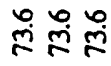

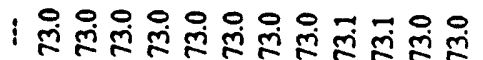

交妾

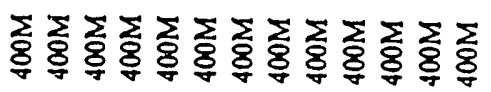

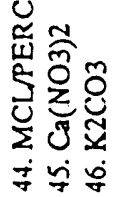

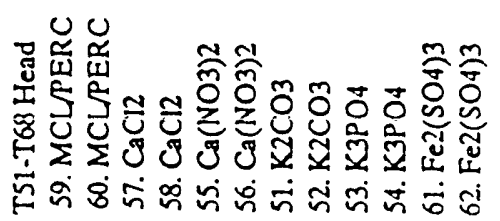

茫

눙ำ

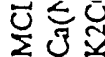

过官迢

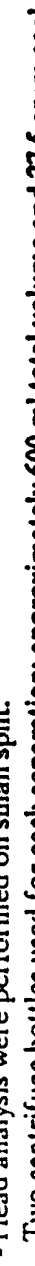


These results were not complete as of the last Quarterly report and are reported in full here. Table IB shows the results for the Final separation Tests, tests $31-66$, conducted with dispersants, which were identical to the Initial Tests except that the optimum dispersants were used for each of the six medias and only the 5 minute centrifuging time was used. Dispersant dosages of 1-4 \#/ton were used as specified through Dr. Jim Hwang's visual coal wetting observations and viscosity measurements. For MCL/PERC, $\mathrm{Ca}(\mathrm{NO} 3)^{2} 2$ and K3PO4, extremely high dosage levels of 40 \#/ton were also tested for the best dispersants. However, these dosages would be impractical for a plant application because of the extremely high cost of the dispersants ( $\$ 10.00-\$ 77.00$ per clean coal ton at those dosage levels).

Centrifuging times of 5 minutes at 3750 RPM were used for all the Final separation Tests due to the fairly insignificant differences in test results for the 5 and 30 minute periods performed in the Initial separation Tests. The differences between the 5 and 30 minute centrifuging times used in the Initial separation Tests were fairly insignificant, particularly when accuracy of test procedures and ASTM analyses are considered. Yields in all cases differed by less than $1.5 \%$, and in most cases less than 1\%. Ash differed by less than $0.20 \%$ in all cases except for one, between the 5 and 30 minute tests.

The purpose of these experiments was to determine the separation performance by yardsticks, such as ash, moisture, and weight splits under time pressure. IGC magnetically enhanced media was not included because it's density is essentially that of water and is not applicable to centrifugal gravimetric separations. Later in this discussion the optimum test results for each media will be compared graphically to the Illinois No. 6 Precleaned Coal washability results to better quantify and compare efficiencies of separations for the various media options and determine desired aqueous solution media for Phase II testing. The following observations can be made based on the results in Table $1 \mathrm{~B}$.

The MCL/PERC media, CaCl2 media and Ca(NO3) 2 media most accurately reconstitute head ash composition. In all cases, reconstituted feed sulfur content was slightly less than original composite head analysis. $\mathrm{K} 2 \mathrm{CO} 3$ and $\mathrm{K} 3 \mathrm{PO} 4$ medias caused a 0.5 - 1.5 ash unit increase in reconstituted head composition due undoubtedly to a combination of inefficient washing and precipitation of ions from solution. Fe2(SO4)3 caused a significant drop in ash content due to the extremely low $\mathrm{pH}$ and enhanced dissolution ions from the coal surface. overall $\mathrm{CaCl} 2$ and $\mathrm{Ca}(\mathrm{NO} 3)_{2} 2$ medias appeared to promote the best reconstitution of head composition.

The MCL/PERC media generally provided lower float product ash, sulfur, and pyritic sulfur contents than the other 
medias, as well as a much lower float product yield indicating that it was separating at a significantly lower gravity.

- Of the aqueous solution medias, $\mathrm{Ca}(\mathrm{NO} 3) 2$ and $\mathrm{Fe} 2\left(\mathrm{SO}_{4}\right) 3$ provided the lowest float ash contents and K3PO4 provided the lowest float sulfur and pyritic sulfur contents. This is particularly true for the $400 \mathrm{M} \times 0$ sample testing.

Comparison to Illinois No. 6 precleaned washability results

As mentioned, the Phase I separation results are compared to the feed coal washability to better assess the relative efficiencies of the various medias. From the Phase I laboratory separations performed with the candidate medias (Table IA $\mathrm{W} / \mathrm{O}$ dispersant, tests $1-24$, and Table $1 B \mathrm{w} /$ dispersants, tests 31 66) an optimum test was selected for each media at $100 \mathrm{M}$ and $400 \mathrm{M}$ topsize. Only the tests at 5 minute time periods were considered as valid options, and the criteria was to select the test which gave the lowest ash and sulfur content in the float product at a given energy recovery level. The optimum tests for each media candidate were then plotted and compared to the grade versus energy recovery relationships for the $100 \mathrm{M}$ and $400 \mathrm{M}$ portions of the washability results (Figures 1 through 6).

\section{Ash versus energy recovery relationships}

Figures 7 and 8 contain plots of the ash versus energy revovery relationships for the $100 \mathrm{M}$ and $400 \mathrm{M}$ topsize grind washability (curves) and the optimum separation tests (the data points). MCL/PERC media had a lower separation gravity than the aqueous solution medias, particularly for the loom topsize samples. In order to accurately quantify the separation gravity float and sink fractions would have to be sized and separated in Certigrav or CsCl medias, to determine the distribution curves for each test. Unfortunately, this testing was outside of the scope of the Phase I Laboratory Testing. However, knowing that the second and third squares on the ash/recovery curve in Figure 7 , represent $1.40 \mathrm{SG}$ and $1.50 \mathrm{SG}$ for the feed sample washability, it appears that the MCL/PERC is separating slightly below the 1.45 media $S G$ and the aqueous solutions are separating at, or slightly higher than $1.45 \mathrm{SG}$.

From the results in Figure 7 , the MCL/PERC and $\mathrm{Ca}$ (NO3) 2 media seem to provide the best ash separation efficiency at $100 \mathrm{M}$ $x$ topsize (shortest horizontal distance between data points and curve). Fe2(SO4) 3 and $\mathrm{CaCl} 2$ are slightly less efficient than $\mathrm{Ca}(\mathrm{NO} 3)_{2} 2$ media for ash separation and the poorest removal efficiency was obtained from the two potassium-based medias ( $\mathrm{K} 2 \mathrm{CO} 3$ and $\mathrm{K} 3 \mathrm{PO} 4$ ). The inefficiency of the potassium medias was partially due to the chemical affinity of the medias for the coal, which promoted residual media on the coal surface and subsequent increase in ash content. 
ASH VIERSUS ENERGY RECOVERY RELATIONSHIP 100M TOPSIZE GRIND WASHABILITY AND OPTIMUM SEPARATION TESTS

(Illinois No. 6 Seam Precleaned Coal)

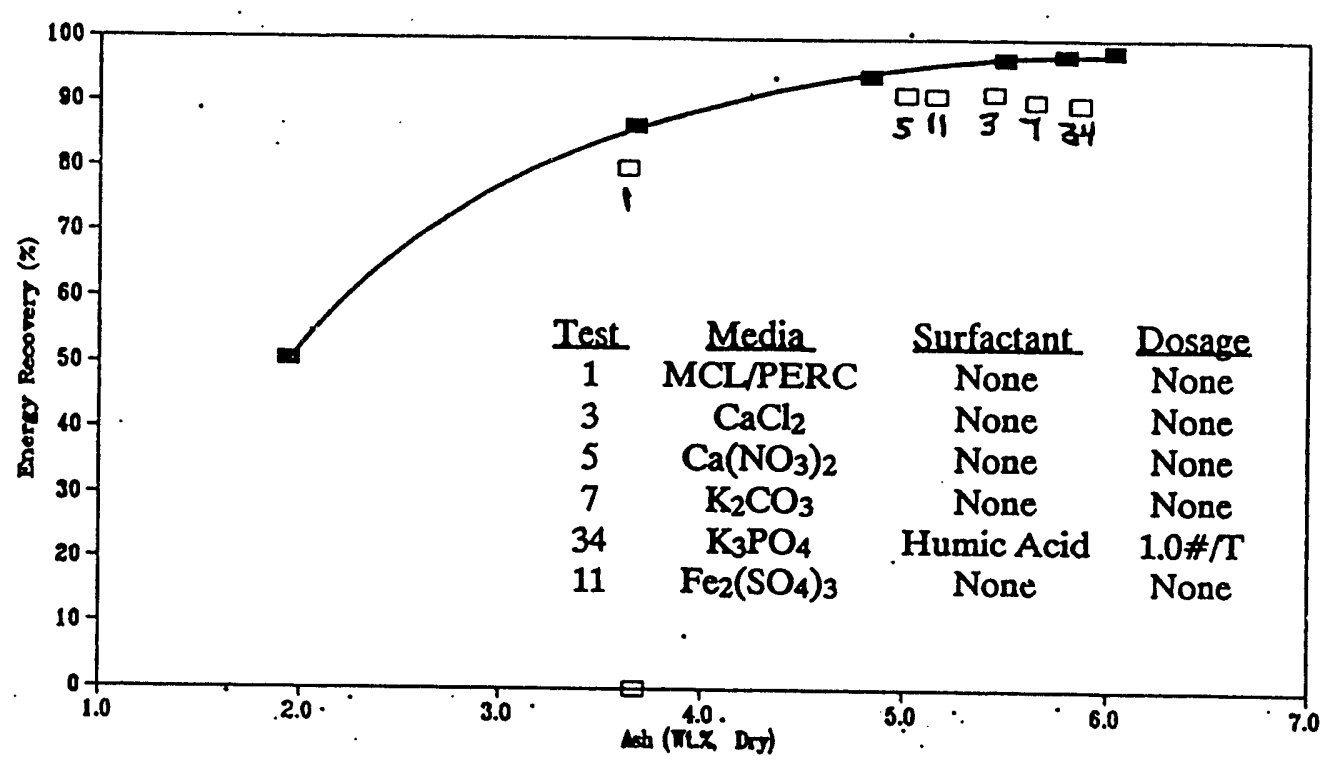

Figure 8

ASH VERSUS ENERGY RECOVERY RELATIONSHIP 400M TOPSIZE GRIND WASHABILITY AND OPTIMUM SEPARATION TESTS (IIlinois No. 6 Seam Precleaned Coal)

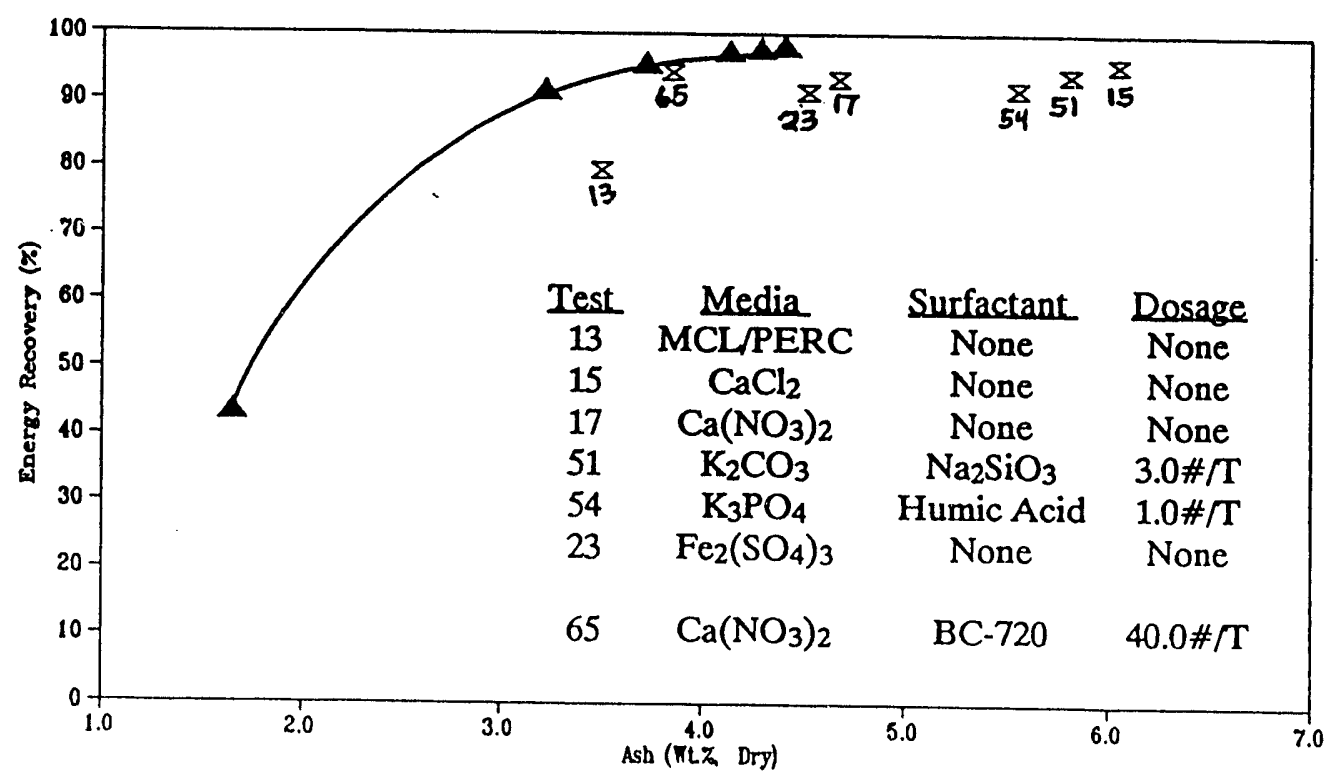


Figure 9

SULFUR VERSUS ENERGY RECOVERY RELATIONSHIP 100M TOPSIZE GRIND WASHABILITY AND OPTIMUM SEPARATION TESTS (Illinois No. 6 Seam Precleaned Coal)

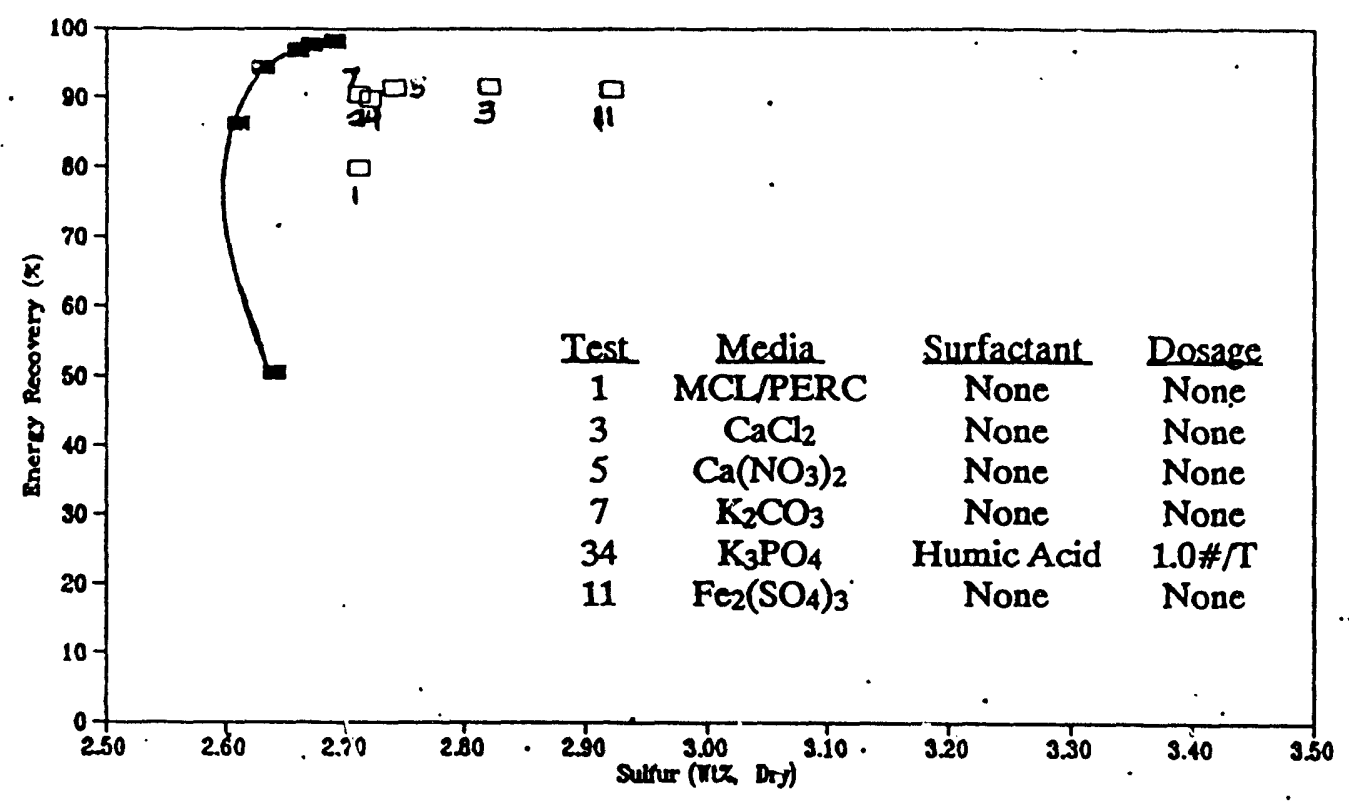

Figure 10

SULFUR VERSUS ENERGY RECOVERY RELATIONSHIP 400M TOPSIZE GRIND WASHABILITY AND OPTIMUM SEPARATION TESTS (Illinois No. 6 Seam Precleaned Coal)

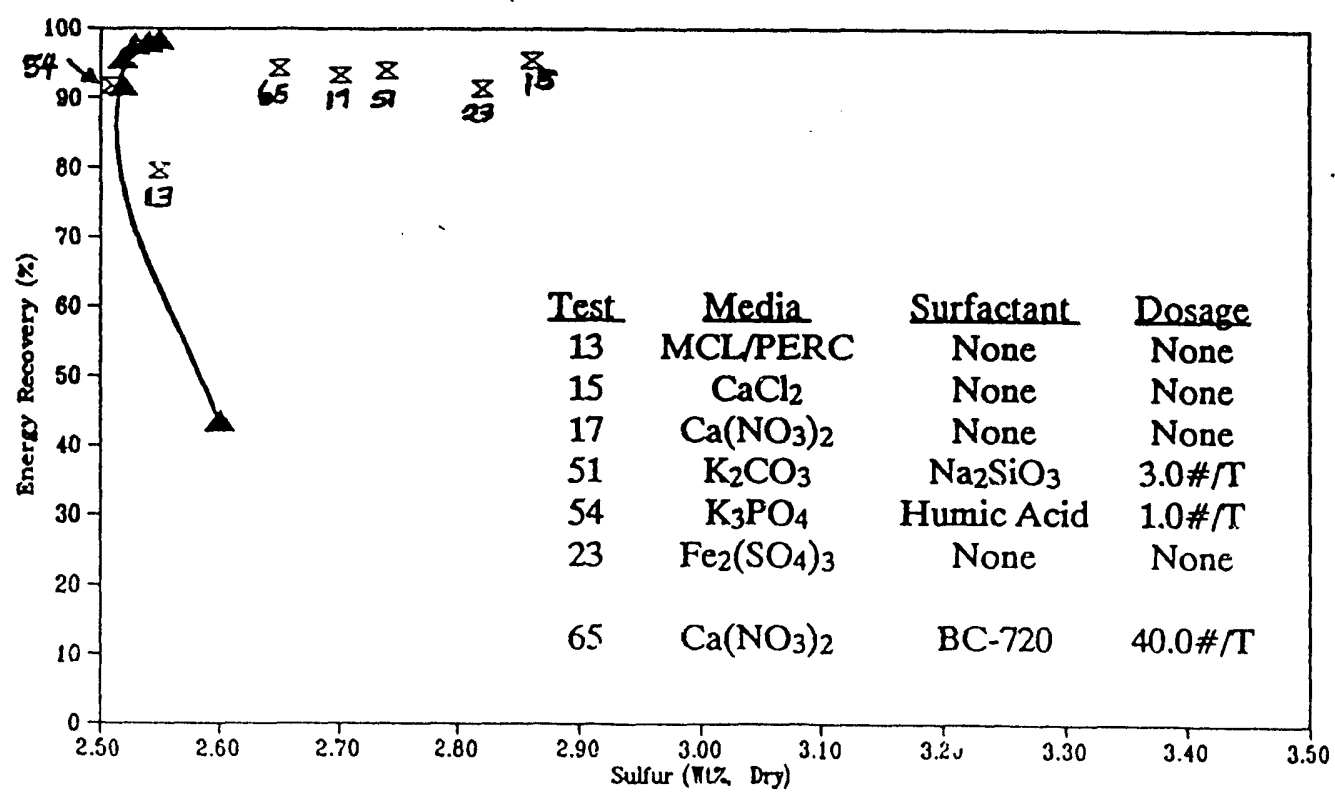


Figure 11

PYRITIC SULFUR VERSUS ENERGY RECOVERY RELATIONSHIP 100M TOPSIZE GRIND WASHABILITY AND OPTIMUM SEPARATION TESTS (Illinois No. 6 Seam Precleaned Coal)

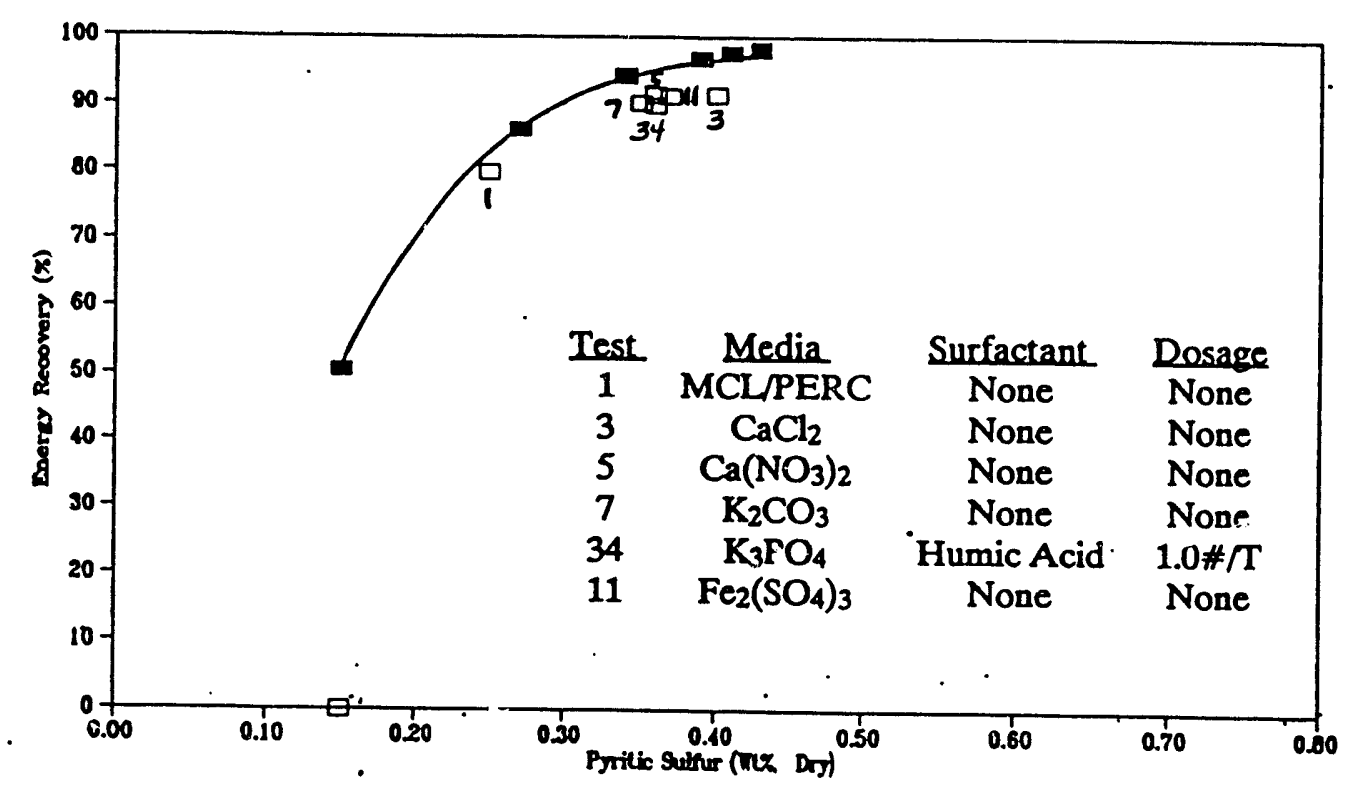

Figure 12

PYRITIC SULFUR VERSUS ENERGY RECOVERY RELATIONSHIP 400M TOPSIZE GRIND WASHABILITY AND OPTIMUM SEPARATION TESTS (Illinois No. 6 Seam Precleaned Coal)

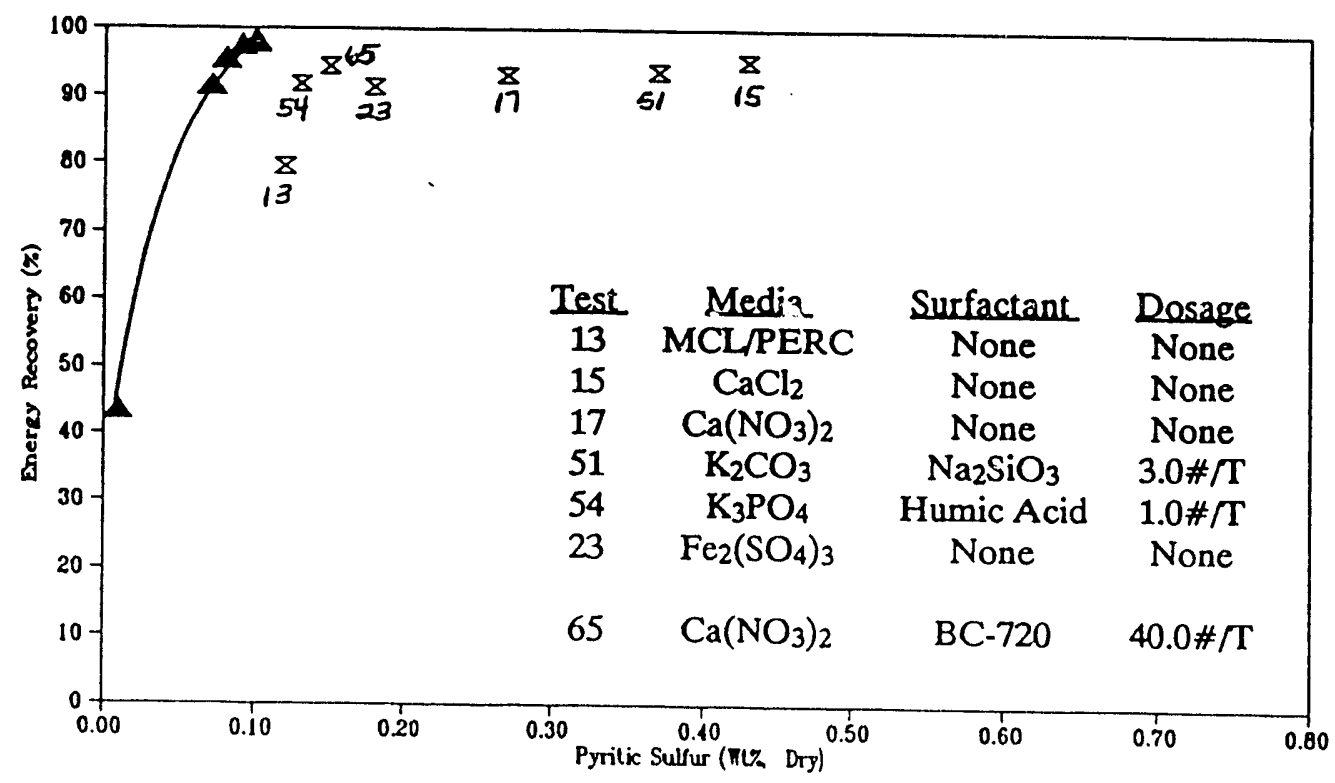


From Figure 8 , it appears that MCL/PERC, Fe:2(SO4) 3 and $\mathrm{Ca}(\mathrm{NO} 3) 2$ are also the best medias for removing ash from the float product, for the $400 \mathrm{M} \times \mathrm{O}$ feed coal. Test 65 (the $\mathrm{Ca}$ (NO3) 2 test with extremely high dispersant dosage) had the best overall ash separation efficiency. However, those dispersant dosages (equating to $\$ 55.00-\$ 77.00$ per ton of clean coal produced) would be impractical for plant applications.

\section{Sulfur versus energy recovery relationships}

In a similar fashion, Figures 9 and 10 contain plots of the sulfur versus energy recovery washability relationship for $100 \mathrm{M}$ and $400 \mathrm{M}$ topsize grind (curve) and the optimum laboratory separation tests using the $100 \mathrm{M} \times 0$ and the $400 \mathrm{M} \times 0$ samples (data points). From the horizontal distances between the data points and the washability curves in Figure 9, it appears that the sulfur removal efficiency for MCL/PERC and three of the aqueous solution medias ( $\mathrm{Ca}(\mathrm{NO} 3) 2, \mathrm{~K} 2 \mathrm{CO} 3$ and $\mathrm{K} 3 \mathrm{PO} 4$ ) are very similar with poorer sulfur removal efficiency for Cacl2 and Fe2 ( $S 04$ ) 3 medias.

For the 400M $\times 0$ topsize tests (Figure 10), the differences were much more dramatic. Test 54, performed with K3PO4, dramatically showed the best sulfur removal efficiency and closely correlated to the washability relationship. The MCL/PERC results (Test 13) also closely correlated to the grade/recovery curve. The eulfur removal efficiencies were less favorable for the test performed with $\mathrm{Ca}\left(\mathrm{NO}_{3}\right) 2$ and $\mathrm{K} 2 \mathrm{CO} 3$ media. The worst results were obtained for Fe2(SO4) 3 and CaCl2 medias, as was the case for the loom $\times 0$ tests.

Pyri=ic sulfur versus energy recovery relationships

Lastly, Figures 11 and 12 contain the pyritic sulfur versus energy recovery washability relationships for $100 \mathrm{M}$ and $400 \mathrm{M}$ topsize grinds (the curves) as well as the optimum laboratory separation results for each media with $100 \mathrm{M}$ and $400 \mathrm{M}$ topsize feeds (the data points). From Figure ll, it appears that MCL/PERC media (Test 1) showed the best efficiency of pyritic sulfur removal at $100 \mathrm{M}$ topsize. The results for the optimum aqueous solution media tests were all fairly similar, yielding float pyritic sulfur contents ranging from 0.35 to $0.40 \%$.

By contrast, the pyritic sulfur removal efficiencies were much more variable for the $400 \mathrm{M}$ topsize tests. As with sulfur content, Test 54 using K3PO4 media showed the best pyritic sulfur removal efficiency with slightly lower efficiencies being obtained from MCL/PERC, Fe2(SO4) 3 and Ca(NO3) 2 medias. The poorest pyritic sulfur removals were obtained with $\mathrm{K} 2 \mathrm{CO}_{3}$ and CaCl2 medias. The high $\mathrm{BC}-720$ dispersant dosage for $\mathrm{Ca}(\mathrm{NO} 3)_{2} 2$ (Test 65) did significantly improve pyritic sulfur removal relative to Test 17 with no dispersant. However, the difference was not as pronounced for total sulfur contents (Figure 10). 
One point of inconsistency was Test 23 , which had a fairly low pyritic sulfur content despite having a high float product sulfur content for the $400 \mathrm{M} \times 0$ tests (see Figure 10). The extremely low pH of Fe2(SO4) 3 and aggressive chemical environment likely oxidized pyrite causing inaccurate pyritic sulfur content measurements. For this reason, the majority of technical evaluation should be on the basis of ash and total sulfur removal efficiencies. Pyritic sulfur removal efficiencies should only be used to better explain total sulfur removals. Therefore, selection of optimum aqueous solution media for Phase II should be based mainly on the results in Figures 7 through 10 .

In summation, it appears that MCL/PERC gave the most consistent separations in terms of ash and sulfur removal. of the aqueous solution media, $\mathrm{Ca}(\mathrm{NO} 3) 2$ and $\mathrm{Fe} 2(\mathrm{SO} 4) 2$ proved to be best for ash removal efficiency. For siulfur removal, the differences between the best aqueous medias ( $\mathrm{Ca}(\mathrm{NO} 3)_{2}, \mathrm{~K}_{2} \mathrm{CO} 3$ and K3PO4) were insignificant for the 100M $x 0$ topsize; K3PO4 proved to be significantly better for $400 \mathrm{M}$ topsize grinds. If the anticipated grind for commercial applications is around $100 \mathrm{M}$ topsize, $\mathrm{Ca}(\mathrm{NO} 3) 2$ media appears to be the best media candidate. However, if finer grinds approaching $400 \mathrm{M}$ topsize are anticipated, either $\mathrm{Ca}\left(\mathrm{NO}_{3}\right) 2$ or $\mathrm{K} 3 \mathrm{PO} 4$ media could be selected, dependant on whether product ash content or product sulfur content is the main consideration.

Part IIIA - Washing Tests, Filter Cake Washing simulation

These tests were expected to indirectly reveal the amount of solvent lost on the coal (residual media on coal), show any filtering problems, or any media interactions with coal. It was speculated that medias in the neutral range would be desired, not only due to less aggressiveness toward materials of construction, but also because they would have less tendency to alter the composition of the coal and water within the plant. High pH medias, such as $\mathrm{K} 2 \mathrm{CO} 3$ and $\mathrm{K} 3 \mathrm{PO} 4$, were speculated to cause precipitation of dissolved calcium and magnesium found in hard water. These ions may precipitate as metal carbonate salts on a coal particulate surface or become mechanically entrapped on the coal and filter media after precipitating out of solution. Consequently, the calcium and magnesium salts would contaminate the coal. Extremely low pH medias, such as Fe2(SO4) 3, were thought to dissolve ash particles within the coal, such as pyrite, and lead to a chemical processing behavior. The pH of the respective media is shown in Table 2 .

Prior to conducting media washing tests, the $100 \mathrm{M}$ and $400 \mathrm{M}$ topsize samples of the Illinois No. 6 Seam Precleaned Coal were slurried in distilled water, filtered, and washed with $500 \mathrm{ml}$ of hot and cold water (as in the normal washing procedure). Table 3 contains the analyses of the coal samples prior to the water washing procedure and after the procedure. As expected, the ash and sulfur contents appeared to drop slightly due to dissolution 
Table 2

$\therefore \quad$ pH MEASUREMENTS OF MEDIAS .

Phase I Media Evaluation

\begin{tabular}{lccc} 
& \multicolumn{3}{c}{$\mathrm{pH} @$ Various Specific Gravitie } \\
Fresh Media & $\frac{1.35}{9.0}$ & $\frac{1.45}{8.0}$ & $\frac{1.55}{8.0}$ \\
$\mathrm{CaCl} 2$ & 5.4 & 4.4 & 5.0 \\
$\mathrm{Ca}(\mathrm{NO} 3) 2$ & 12.5 & 12.5 & 13.6 \\
$\mathrm{~K} 2 \mathrm{CO} 3$ & 12.8 & 13.1 & 13.3 \\
$\mathrm{~K} 3 \mathrm{PO} 4$ & 0.2 & -0.2 & -0.4 \\
$\mathrm{Fe} 2$ (SO4)3 & & & \\
& $\underline{1.30}$ & $\underline{1.40}$ & $\underline{1.60}$ \\
$\mathrm{CsCl}$ (Fresh) & 6.3 & 6.3 & 6.4 \\
$\mathrm{CsCl}$ (Used) & 4.4 & 5.4 & 7.4
\end{tabular}

IGC Fluid "A" (1.0125 SG)

IGC Fluid "B" (1.0125 SG) $\quad 8.7$

Note: All medias made using distilled water 
Table 3

WATER WASHING TESTS

Phase I Media Evaluation

I. COAL SAMPLE ANALYSIS

\begin{tabular}{ccc} 
& \multicolumn{2}{l}{ Il \#6 Seam Coal } \\
Test No. & $\frac{\text { Topsize }}{\text { Weight }}$ & (grams) \\
\hline 1 & $\frac{100 \mathrm{M}}{75}$ & . \\
2 & $400 \mathrm{M}$ & 75
\end{tabular}

Washing Quantities

Hot $\mathrm{H} 2 \mathrm{O}$ Cold $\mathrm{H} 2 \mathrm{O}$

$\frac{(\mathrm{ml})}{500} \quad \frac{(\mathrm{ml})}{500}$

Dry Ash (Wt\%) Dry Sulfur (Wt\%)

$2 \quad 400 \mathrm{M} \quad 75$

$500 \quad 500$

$\frac{\text { Before }}{10.57} \quad \frac{\text { After }}{10.53}$

Before - After

$500 \cdot 500$

$\begin{array}{llll}10.66 & 10.61 & 3.66 & 3.58\end{array}$

II. WATER SAMPLE ANALYSIS

Test No. Description

$1 \& 2$ Virgin Distilled Water

Quantity Coal

\begin{tabular}{|c|c|c|c|c|c|c|c|}
\hline & & & & IIIMT & on $(\mathrm{PF}$ & & \\
\hline$\frac{(\dot{m} \mathrm{l})}{6 n}$ & Topsize & $\mathrm{Na}$ & $\underline{\mathrm{K}}$ & $\mathrm{Fe}$ & $\mathrm{Mg}$ & $\mathrm{Ca}$. & $\underline{\mathrm{SO} 4}$ \\
\hline
\end{tabular}

1 Initial Filtrate

1 Hot Water Wash

1 Cold Water Wash

$\begin{array}{llllllll}600 & 100 \mathrm{M} & 7.79 & 2.65 & <0.06 & 2.28 & 38.76 & 136.0\end{array}$

$\begin{array}{llllllll}500 & 100 \mathrm{M} & 3.37 & 0.65 & 0.14 & 0.52 & 5.48 & 15.9\end{array}$

2 Initial Filtrate

2 : Hot Water Wash

500. $100 \mathrm{M}$

$\begin{array}{lllllllll}600 & 400 \mathrm{M} & 7.49 & 1.86 & <0.06 & 2.34 & : 61.20 & 187.0\end{array}$

2 Cold Water Wash

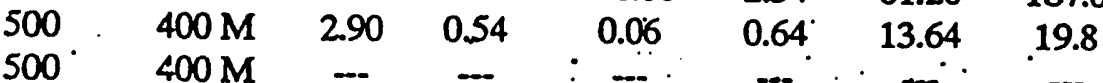




\section{Table 4 \\ MEDIA WASHING TESTS \\ Phase I Media Evaluation}

A. PROCEDURES AND COAL ASH AND BTU/LB ANALYSES:

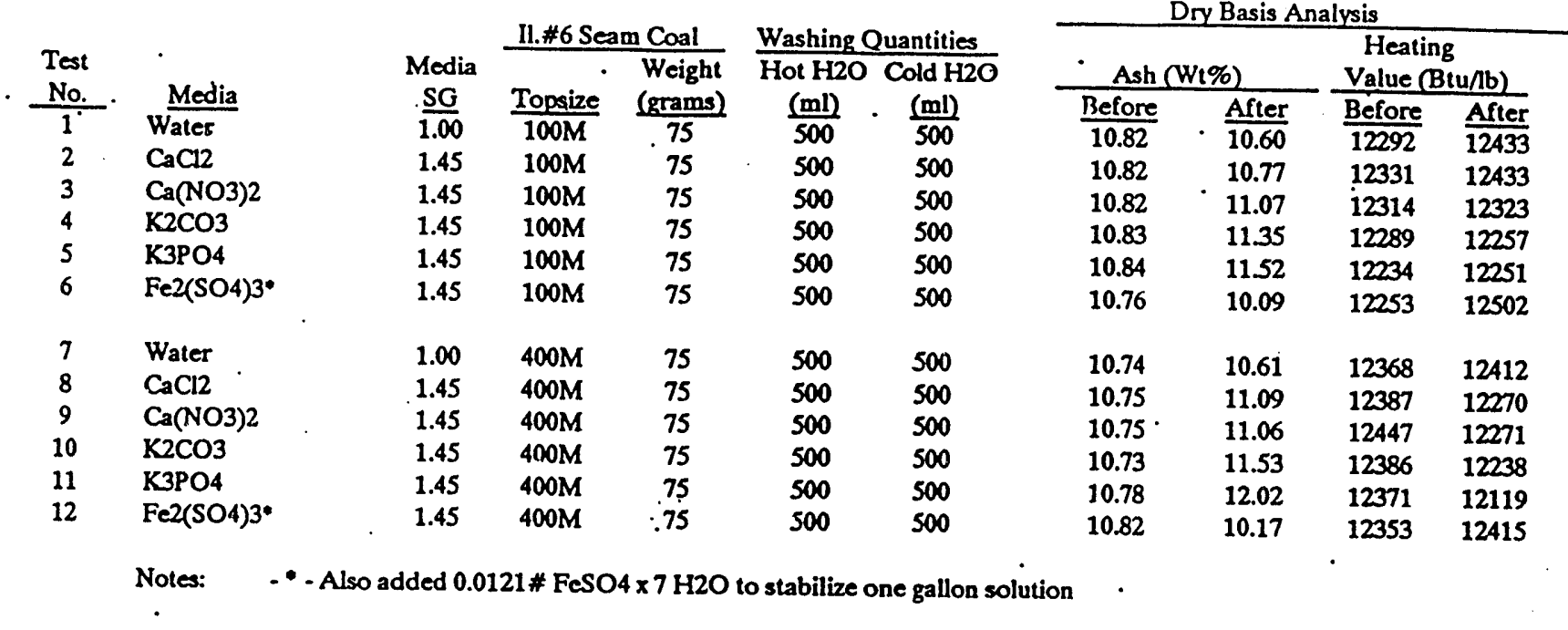

B. COAL ELEMENTAL ANALYSES: (From dissolution and atomic absorption analysis)

\begin{tabular}{|c|c|c|c|c|c|}
\hline No. & Sample & Media & \% Ca & \%즈 & \% Fe \\
\hline 2.6 & Combined Heads & None & $\overline{0.04}$ & 0.17 & 1.24 \\
\hline 2 & Final Coal Product & $\mathrm{CaCl} 2$ & 0.03 & - & - \\
\hline 3 & Final Coal Product & $\mathrm{Ca}(\mathrm{NO} 3)_{2}$ & 0.03 & - & - \\
\hline 4 & Final Coal Product & $\mathrm{K} 2 \mathrm{CO}_{3}$ & - & 0.41 & - \\
\hline 5 & Final Coal Product & K3PO4 & - & 0.42 & - \\
\hline 6 & Final Coal Product & $\mathrm{Fe} 2\left(\mathrm{SO}_{4}\right) 3$ & - & - & 1.26 \\
\hline $8-12$ & Combined Heads & None & 0.52 & 0.16 & 1.14 \\
\hline 8 & Final Coal Product & $\mathrm{CaCl} 2$ & 0.04 & - & - \\
\hline 9 & Final Coal Product & $\mathrm{Ca}(\mathrm{NO} 3) 2$ & 0.02 & - & - \\
\hline 10 & Final Coal Product & $\mathrm{K} 2 \mathrm{CO} 3$ & - & 0.44 & - \\
\hline 11 & Final Coal Product & $\mathrm{K} 3 \mathrm{PO} 4$ & - & 0.47 & - \\
\hline 12 & Final Coal Product & $\mathrm{Fe} 2(\mathrm{SO} 4) 3$ & $\ldots$ & - & 1.26 \\
\hline
\end{tabular}

Comments - Water wash led to slight drop in ash and increase in Btu/1b, perhaps due to ions leached out of coal (see Table 2).

- Calcium medias led to slight, if even significant, increase in ash content (0.0-0.3\%); not due to insufficient washing but probably due to some ions precipitating out of water at high ionic strength.

- Potassium medias led to significant increase in ash content (0.5-1.3\%), due to chemical affinity of the media to coal, which resulted in insufficient washing (0.4-0.5\% ash content increase), coupled with magnified precipitation of ions from water at high pH (see Table 1) which caused the remainder of ash content increase. Precipitation was magnified for $400 \mathrm{M} \times 0$ samples.

- $\mathrm{Fe} 2(\mathrm{SO} 4) 3$ media washed well like calcium medias, but extremely low $\mathrm{pH}$ (see Table 1) led to magnified dissolution $o f$ ions from coal and significant drop in coal ash content $(0.6-0.7 \%)$. 
of mineral ions into the water. The water analyses for the virgin distilled water, the initial filtrates, and hot water wash for both coal topsizes also qualitatively show the increase in ion concentration in the water for the initial filtrate and hot water washes, proving that ions are indeed dissolved from the coal.

The final set of washing tests was done with five aqueous solution medias that were being tested. The same procedures were again followed as with the water washing tests, in that the tests were performed with both $100 \mathrm{M}$ and $400 \mathrm{M}$ topsize Illinois No. 6 Seam Precleaned Coal and washing quantities of $500 \mathrm{ml}$ of hot and cold water were used. Table 4 contains the procedures, ash contents, and heating value analysis before and after the washing terts. Part B also contains elemental analyses of the key cation constituents in the various medias to quantify residual media remaining on the coal. The following conclusions can be drawn from the test results:

Water washing led to a slight decrease in ash content and increase in heating value probably due to slight ion dissolution from the coal.

The calcium medias ( $\mathrm{CaCl} 2$ and $\mathrm{Ca}(\mathrm{NO} 3)_{2}$ ) led to a slight, if even significant, increase in ash content after the testing (0.0 - 0.3 units). The percent calcium in the combined heads and final coal products indicate that this slight increase in ash content was not due to insufficient calcium washing, but probably due to some precipitation of other ions out of the water at the high salt concentrations.

The potassium medias ( $\mathrm{K} 2 \mathrm{CO} 3$ and $\mathrm{K} 3 \mathrm{PO} 4$ ) both led to a significant increase in ash content after the testing $(0.5-$ 1.3 units). The ash content increases were also magnified for the $400 \mathrm{M} \times 0$ samples relative to the $100 \mathrm{M} \times 0$ samples. The increase in potassium content of the coal (shown in Part B) indicates that there was a stronger chemical affinity of the potassium medias to the coal, which resulted in insufficient washing and increased ash content (probably 0.4 - 0.5 ash units increase). The remaining increase in ash was probably due to precipitation of other ions from the water at the high $\mathrm{pH}(12.5-13.6)$ and salt concentration of the medias.

Fe2(SO4) 3 media was sufficiently washed from the coal, as were the calcium medias. This is shown by the consistent head and final product iron contents in part $B$. However, the extremely low pH (less than l) of the Fe2 (SO4) 3 media led to magnified dissolution of ions from the coal and a significant drop in ash content after the testing $(0.6-0.7$ ash units). 
In summation, the washing and dissolution behavior of the medias is a factor that must be considered when selecting an optimum media. Medias which wash well and reconstitute composition would obviously be desired for any laboratory procedures, but would also be beneficial for plant applications. obviously, extremely high or extremely low pH medias which cause chemical processing behavior in the plant are undesirable. CaCl2 and $\mathrm{Ca}(\mathrm{NO} 3) 2$ have a distinct advantage from both a washing efficiency and coal composition consistency perspective.

\section{Part IIIB - Solvent Recovery Tests}

These tests were intended to compare the effectiveness and partly the economics of two media recovery options for organic media, thermal drying and hot water flash. Each of the four precleaned test coals was first treated in a methylene chloride (MCL) and perchloroethylene (Perc) mixture at two gravities, 1.35, and 1.55. Recovery effectiveness was simulated in the laboratory by immersing ground 100 Mesh $x 0$ coal samples in an organic mixture of $92.6 \%$ MCL \& $7.4 \%$ Perc ( $1.35 \mathrm{SG}$ ), or $18.5 \% \mathrm{MCL}$ $\& 81.5 \%$ Perc ( $1.55 \mathrm{SG}$ ) and then subjecting the resultant slurry to one of the two recovery methods. DOW Laboratories then measured the residual media on the coal to determine the lowest residual.s that can be achieved with both methods.

Results of these tests are shown in Table 5. The table also contains the procedures and results obtained from the eight tests performed with the straight thermal drying and hot water process options. In the straight thermal drying process, the slurry was filtered and completely dried at $107^{\circ} \mathrm{C}$ to simulate complete thermal drying. The cake was then analyzed for residual MCL and PERC remaining in parts per million and the losses were equated to a \$/Ton basis.

A similar approach was followed for the hot water process samples except after initial filtering the cakes were slurried in 94-97 ${ }^{\circ} \mathrm{C}$ hot water for ten minutes, then again filtered and dried to completion at $107^{\circ} \mathrm{C}$. The results in Table 5 show the final residual MCL and PERC remaining on the coal samples as well as the appropriate cost of the solvent losses. In addition, the filtrate water samples were also analyzed by Dow Chemical for residual media in parts per million. Part II.B of Table 5 contains the calculation of combined solvent losses ( $\$ /$ Ton) for coal and water, assuming 5, 10, 20, and $30 \%$ residual moisture content on the final coal product.

It is interesting to note that the residual media content on the coal were much more dependant on the characteristics of the coal than the process which was used. For both processes, Illinois No. 6 seam Precleaned coal led to the highest residual media contents on the coal, probably due to its lower rank. The optimum losses, in the straight thermal drying process, were between $\$ 1.01$ and $\$ 1.53$ per ton of coal processed, and the optimum losses for the hot water processed samples were between 
Table 5

\section{OPTIMAL ORGANIC SOLVENT \\ MEDIA RECOVERY TESTINIG}

(Methylene chloride (MCL) and Perchloroethylene (PERC) mixture)

IS Solvent Losses In Straight Thermal Drying Samples:

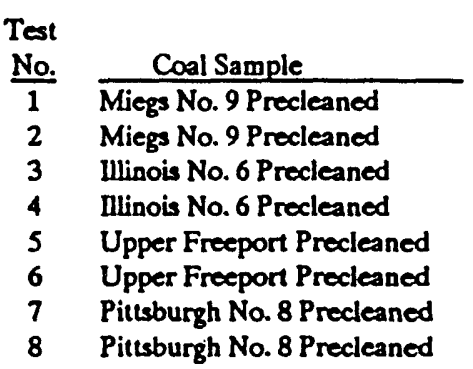

$60 \mathrm{M} \times 0$ samples treated in MCLPERC mixture media, then filtered and dried to completion at 107 degrees $C$.

Dow's Measurement Of

Solvents On Dried Coal Cost Of Solvent On Coal *

SG of

$\frac{\text { Media }}{135}$

1.35

1.55

1.35

1.55

1.35

1.55

1.35

1.55 (ppm) (ppm)

$118 \quad 924$

$38 \quad 382$

$68 \quad 2644$

$40 \quad 1760$

$132 \quad 218$

$76 \quad 307$

- 109280

$65 \quad 224$
MCL PERC

\begin{tabular}{|c|c|c|}
\hline $\begin{array}{c}\mathrm{MCL} \\
\text { (S/Ton) }\end{array}$ & $\begin{array}{l}\text { PERC } \\
\text { (S/Ton) }\end{array}$ & $\begin{array}{c}\text { Total } \\
\text { (\$/Ton) })\end{array}$ \\
\hline 0.07 & 0.52 & 0.59 \\
\hline 0.02 & 0.21 & 0.23 \\
\hline 0.05 & 1.48 & 1.53 \\
\hline 0.02 & 0.99 & 1.01 \\
\hline 0.07 & 0.12 & 0.19 \\
\hline 0.04 & 0.17 & 0.21 \\
\hline 0.06 & 0.16 & 0.22 \\
\hline 0.04 & 0.13 & 0.17 \\
\hline
\end{tabular}

- Assumed bulk media costs of \$0.28/hb for both MCL and PERC.

iI. Hot Water Process Samples: $60 \mathrm{M} \times 0$ samples treated in MCL/PERC mixture media and filtered, then dropped in 94-97 degrees C hot water, then filtered and dried to completion at 107 degrees $C$.

A. Solvent Losses Assuming Complete Drying ( $0.0 \% \mathrm{H} 2 \mathrm{O}$ )

Dow's Measurement Of

\begin{tabular}{|c|c|c|}
\hline $\begin{array}{l}\text { Test } \\
\text { No. }\end{array}$ & Coal Sample & $\begin{array}{l}\text { SG of } \\
\text { Media }\end{array}$ \\
\hline 9 & Miegs No. 9 Precleaned & 1.35 \\
\hline 10 & Miegs No. 9 Precleaned & 1.55 \\
\hline 11 & Illinois No. 6 Precleaned & 1.35 \\
\hline 12 & Illinois No. 6 Precleaned & 1.55 \\
\hline 13 & Upper Freeport Precleaned & 1.35 \\
\hline 14 & Upper Freeport Precleaned & 1.55 \\
\hline 15 & Pittsburgh No. 8 Precleaned & 1.35 \\
\hline 16 & Pittsburgh No. 8 Precleaned & 1.55 \\
\hline
\end{tabular}

Solvents On Dried Coal

\begin{tabular}{|c|c|c|c|c|}
\hline \multicolumn{2}{|c|}{ Solvents On Dried Coal } & \multicolumn{3}{|c|}{ Cost Of Solvent On Coal } \\
\hline $\begin{array}{l}\mathrm{MCL} \\
\text { (ppm) }\end{array}$ & $\begin{array}{l}\text { PERC } \\
\text { (ppm) }\end{array}$ & $\begin{array}{c}\text { MCL } \\
\text { (S/Ton) }\end{array}$ & $\begin{array}{l}\text { PERC } \\
\text { (S/Ton) }\end{array}$ & $\begin{array}{l}\text { Total } \\
\text { (S/Ton) }\end{array}$ \\
\hline 146 & 769 & 0.08 & 0.43 & 0.51 \\
\hline 36 & 215 & 0.02 & 0.12 & 0.14 \\
\hline 37 & 1146 & 0.02 & 0.64 & 0.66 \\
\hline 34 & 1469 & 0.02 & 0.82 & 0.84 \\
\hline 103 & 288 & 0.06 & 0.16 & 0.22 \\
\hline 82 & 260 & 0.05 & 0.15 & 0.20 \\
\hline 38 & 119 & 0.02 & 0.07 & 0.09 \\
\hline 73 & 231 & 0.02 & 0.13 & 0.15 \\
\hline
\end{tabular}

- Assumed bulk media costs of \$0.28/b for both MCL and PERC.

B. Solvent Losses Assuming Incomplete Drying

\begin{tabular}{|c|c|c|c|c|c|c|c|c|c|c|}
\hline \multirow[b]{2}{*}{$\begin{array}{l}\text { Test } \\
\text { No. }\end{array}$} & \multirow[b]{2}{*}{ Coal Sample } & \multirow[b]{2}{*}{$\begin{array}{l}\text { SG of } \\
\text { Media }\end{array}$} & \multicolumn{2}{|c|}{$\begin{array}{l}\text { Coal and Water } \\
\text { At } 5 \% \mathrm{H} 2 \mathrm{O}\end{array}$} & \multicolumn{2}{|c|}{$\begin{array}{c}\text { Coal and Water } \\
\text { At } 10 \% \mathrm{H} 2 \mathrm{O}\end{array}$} & \multicolumn{2}{|c|}{$\begin{array}{l}\text { Coal and Water } \\
\text { At } 20 \% \mathrm{H} 2 \mathrm{O}\end{array}$} & \multicolumn{2}{|c|}{$\begin{array}{l}\text { Coal and Water } \\
\text { At } 30 \% \text { H2O }\end{array}$} \\
\hline & & & $\begin{array}{l}\text { Low } \\
\text { (S/Ton) }\end{array}$ & $\begin{array}{c}\text { High } \\
\text { (S/Ton) }\end{array}$ & $\begin{array}{l}\text { Low } \\
\text { (S/Ton) }\end{array}$ & $\begin{array}{l}\text { High } \\
\text { (S/Ton) }\end{array}$ & $\begin{array}{l}\text { Low } \\
\text { (\$/Ton) }\end{array}$ & $\begin{array}{c}\text { High } \\
\text { (S/Ton) }\end{array}$ & $\begin{array}{l}\text { Low } \\
\text { (\$/Ton) }\end{array}$ & $\begin{array}{l}\text { High } \\
\text { (S/Ton) }\end{array}$ \\
\hline$\overline{9}$ & Miegs No. 9 Precleaned & 1.35 & 0.51 & 0.51 & 0.51 & 0.52 & 0.52 & 0.53 & 0.52 & 0.54 \\
\hline 10 & Miegs No. 9 Precleaned & 1.55 & 0.14 & 0.14 & 0.14 & 0.15 & 0.15 & 0.16 & 0.15 & 0.17 \\
\hline 11 & Illinois No. 6 Precleaned & 1.35 & 0.66 & 0.66 & 0.66 & 0.67 & 0.67 & 0.68 & 0.67 & 0.69 \\
\hline 2 & Illinois No. 6 Precleaned & 1.55 & 0.84 & 0.84 & 0.84 & 0.85 & 0.85 & 0.86 & 0.85 & 0.87 \\
\hline 3 & Upper Freeport Precleaned & 1.35 & 0.22 & 0.22 & 0.22 & 0.23 & 0.23 & 0.24 & 0.23 & 0.25 \\
\hline 14 & Upper Freeport Precleaned & 1.55 & 0.20 & 0.20 & 0.20 & 0.21 & 0.21 & 0.22 & 0.21 & 0.23 \\
\hline 15 & Pittsburgh No. 8 Precleaned & 1.35 & 0.09 & 0.09 & 0.09 & 0.10 & 0.10 & 0.11 & 0.10 & 0.12 \\
\hline 16 & Pittsburgh No. 8 Precleaned & 1.55 & 0.15 & 0.15 & 0.15 & 0.16 & 0.16 & 0.17 & 0.16 & 0.18 \\
\hline
\end{tabular}

- Assuming low and high levels of solvent contamination in the water of 50-150 ppm for MCL and 3-9 ppm for PERC, based on filtrate water analyses performed by Dow Chemical's Laboratories. 
$\$ 0.66$ and $\$ 0.84$ for the same Illinois No. 6 Seam Precleaned Coal. The losses (up to 1000's of parts per million) are significant and may lead to an environmental concern, but are by no means cost prohibitive and do not limit the economic feasibility of trie process. It is also interesting to note that the solvent contamination levels in the water (50-150 ppm MCL and 3-9 ppm PERC) are fairly insignificant as compared to the losses on the coal surface. This can be shown by the similarity of overall costs of $0 \%$ moisture left on the coal and $30 \%$ moisture left on the coal ( $\$ 0.03 /$ Ton difference).

The four feed coals used in these organic solvent recovery tests represents the combined clean coal and reject streams from an advanced cleaning process. While proportionally more losses would be expected on the clean coal side and less on the reject side of the media recovery circuits, these experimental results should closely approximate the total losses from both recovery circuits. Clean coal is anticipated to have a greater affinity for organic solvent as compared to ash bearing minerals.

Based on these results it appears that either process would be acceptable in terms of solvent lost on the coal surface. However, the hot water process appears to provide significantly lower theoretical losses of solvent and may provide for a more environmentally acceptable system. The two stages of filtering required for the hot water process will undoubtedly lead to higher capital costs for the plant circuit. However, better controls of solids and vapor flow should make for easier and less expensive operations, particularly in terms of solvent

replacement costs due to vapor losses from the plant system.

\section{Aqueous Solution Media Recovery Option}

A total of 7 vendors were contacted in order to help ascertain the cost, applicability, feasibility, efficiency and degree of cooperation (vendor tests) to select the equipment for an aqueous media recovery circuit. The seven vendors were:

1). Bird Machine Company

2). Ore Sorters (North American) Inc., (OSNA)

3). Westech Engineering, Inc.

4). Boliden Allis Canada, Inc. Sala Machine Works Division

5). Dorr-oliver, Inc.

6). Eimco Processing Equipment Company

7). Enviro-clear

The envisioned aqueous media recovery circuit would require separate filters for the refuse and clean coal slurry products with multistage washing requirements within the filters to maintain the aqueous solution media at acceptable levels in the final clean coal and refuse filter cakes. The dilute media obtained from the washings would need to be reconstituted to the appropriate gravity using a water evaporation system and the condensed steam from the evaporators would be reused as an 
initial hot water or possibly a steam wash in the multistage filters.

The machines recommended for the application were of two designs, the Bird-Young Rotary Filter and horizontal belt vacuum filter. Both type of filters offer washing capabilities. All vendors perform their own bench-scale vendor testing, which includes filtration and washing tests. Three of the four manufacturers perform steam drying during vendor testing. Bird Manufacturing Company would be the only company able to perform continuous testing or a small unit during the vendor test period of December 1991 - January 1992. WesTech Engineering, Inc. is the only vendor that would provide a rental agreement (with a 20 week notice); all others are strictly purchases. In regards to purchase availability, Enviro-Clear stated that they could meet a July 1992 deadline, WesTech needs a 20 week notice, Bird and OSNA would be tight and are not sure or committing. All four manufacturers offer technical assistance, but none have the costs incorporated into their purchase price.

After evaluating the information it was concluded that the Bird Machine Company unit offers more testing prior to installation. However, flexibility is lost during operation. In a proof-of-concept plant, flexibility must exist as testing covers a multitude of parameters. As operators familiarize themselves with equipment, adjustments become easier. It is believed that the horizontal belt vacuum filter will be more flexible because an operator can visually assess when to make adjustments. Since all three horizontal belt vacuum filter manufacturers are currently selling and installing units based on bench-scale leaf testing, one has to believe that leaf testing is sufficient. Therefore our recommendation is to use horizontal belt vacuum filters, of which Enviro-clear offers the best pricing, and to vendor test with Enviro-clear during Phase II.

\section{Phase II Separating Media Testing}

The project team will utilize the media selected at the end of Phase I (mcl/perc and aqueous calcium nitrate) with several types of separators in performing the separating media tests. one of these separators has been under development by IGC specifically to be used with magnetically enhanced media and housed within a permanent magnet. However, IGC has had less success than hoped and are doubtful to be represented during Phase II. The separators under development by IGC are a Dynawhirlpool type separator and an elongated cylindrical section cyclone. The problem is not with the fluid, for IGC uses the same fluid in their commercially successful $1001 \mathrm{~b} / \mathrm{hr}$ separator based on mechanically derived centrifugal forces nor is the problem with the separator, for the newly developed separators work well with true heavy liquids. Also, when ordinary water is used (equivalent to MEM fluid without magnetic force) all the particles, "heavies," report to the underflow for a separation. However, with MEM media and the magnet no separation occurs. The 
Table 6

TESTING PLAN

PHASE II MEDIA EVALUATION

Closed-Loop Testing at PTI

. TEST MATRIX: (The Project Team will select one of options 3A or 3B)

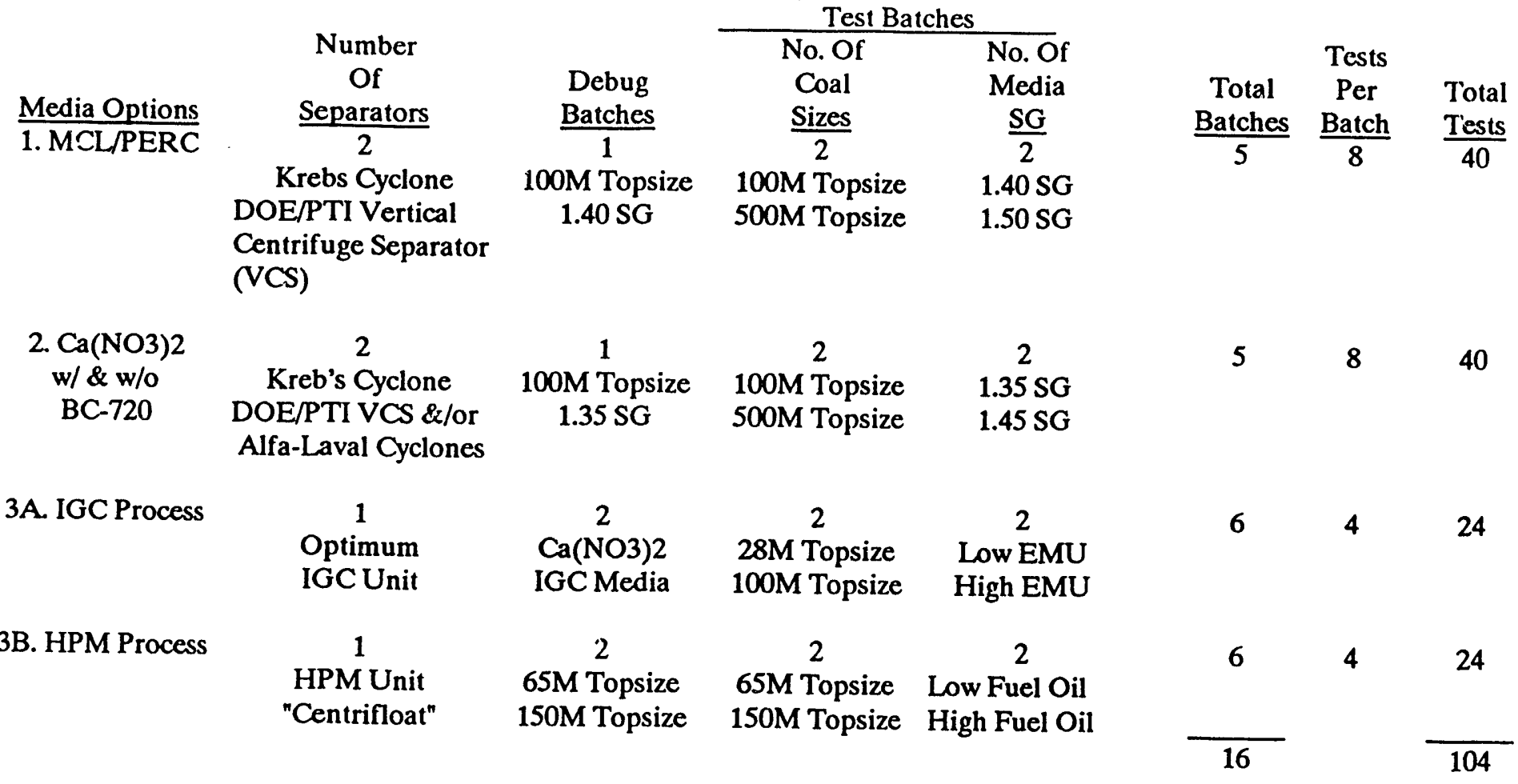

* IMP will also conduct zeta potential and wettability (contact angle and visual dispersion) measurements of coal in the three medias and compare to water to assess affect of particle interactions in the various fluids.

L. TEST VARIABLES: (Target $1000 \# / \mathrm{hr}$ solids feed rate at $7.5 \%$ solids for all units except IGC separator which will run at only $100-500 \# / h r$ )

$\frac{\text { Separator }}{4^{n} \text { Krebs Cyclone }}$

4" DOE/PTI Vertical

Centrifuge Separator (VCS)

Alfa-Laval Cyclones

IGC Separator

HPM Centrifloat

\section{Test Variable \\ Feed Pressure \\ Apex Diameter \\ Feed Inlet Area \\ Feed Line Size \\ Throughput \\ Feed Pressure}

Feed Pressure

Solids Feed Rate

Feed Pressure

Apex Setting

Vortex Selting

Feed Pressure

Air Rate
Range

10-30 PSI

$1 / 2^{n}-3 / 4^{n}$

$0.20-0.50$ Sq. In.

$1^{n}-11 / 2^{n}$

250-1000\#/hr.

10-30 PSI

Unknown

$500-1500 \# / \mathrm{hr}$.

5-20 PSI

Unknown

Unknown

3-10 PSI

Unknown 
problem stems from matching the un-ordered flow profile within the hydraulically powered separator to the ordered magnetic field of the permanent magnet. The project team plans on utilizing Hydroprocessing's Centrifloat to fill the gap left by the impending withdrawal of IGC.

PTI is preparing their process bay for the Phase II tests. The separators and the test plan for Phase II appears on the next page in Table 6 .

Though the DOE/PTI centrifuge was dropped from this program when it failed to meet expectations during PTI's SBIR program, (please refer to PTI's SBIR Final Report "Development and Testing of a Vertical Centrifuge Separator for Density-Based Fine Coal Separations," DOE Project NO. DE-FG02-90ER0971) it was picked up again for a number of reasons. Revelations concerning problems in acquiring an organic compatible separator from $A-L$ on a timely basis and requirements for a 25 micron top feed size first led to the reconsideration of the DOE/PTI centrifuge. Specifically, the 25 micron top size requirement and possible incompatibility with organics effectively eliminates the $A-L$ separator from $3 / 4$ ths of the test matrix. Plastic "miniclones" are available, and will obtained, but their compatibility with organics is uncertain, although it will be checked. The 25 micron requirement led to the decision to grind to the finer feed size of 500M. Michigan Technological University's Institute of Material Processing will complete the grinding to 500M. Had a larger size been selected it would have virtually eliminated all testing applications for an A-I separator. Finally, it is also believed that optimizations (modifications) to the DOE/PTI centrifuge, described below, will improve its performance to a desirable level. It should be noted that without these modifications the
DOE/PTI centrifuge would not be under consideration.

Modifications to PTI's SBIR machine are primarily intended to alleviate separation inefficiency believed to be caused by turbulence and remixing of the streams in the bottom unpartitioned area. A diagram of the DOE/PTI centrifuge is shown in Figure 13. Modifications consist of extending the partition into the discharge area, fabricating a slip fit collar to slide over the newly extended partition to mate to the vortex finder and increasing the angle on the lowest discharge section from 2 to 5 degrees to make volume splits more sensitive to vertical apex movement. The RPM of the machine was also increased.

\section{Task 7 - Data Analysis and Reporting}

Task Description or objective(s): This task is implemented throughout the project to keep up with the day to day logging of data. Dissemination of data to the project team members is vital to the project. Analysis and interpretation of the data is also an important part of this task. Various reports are required during the entire project. Technical reports required under the 
Figure 13

5
5
5
5
8
5
5
5
5
5
5
5
2
2
2

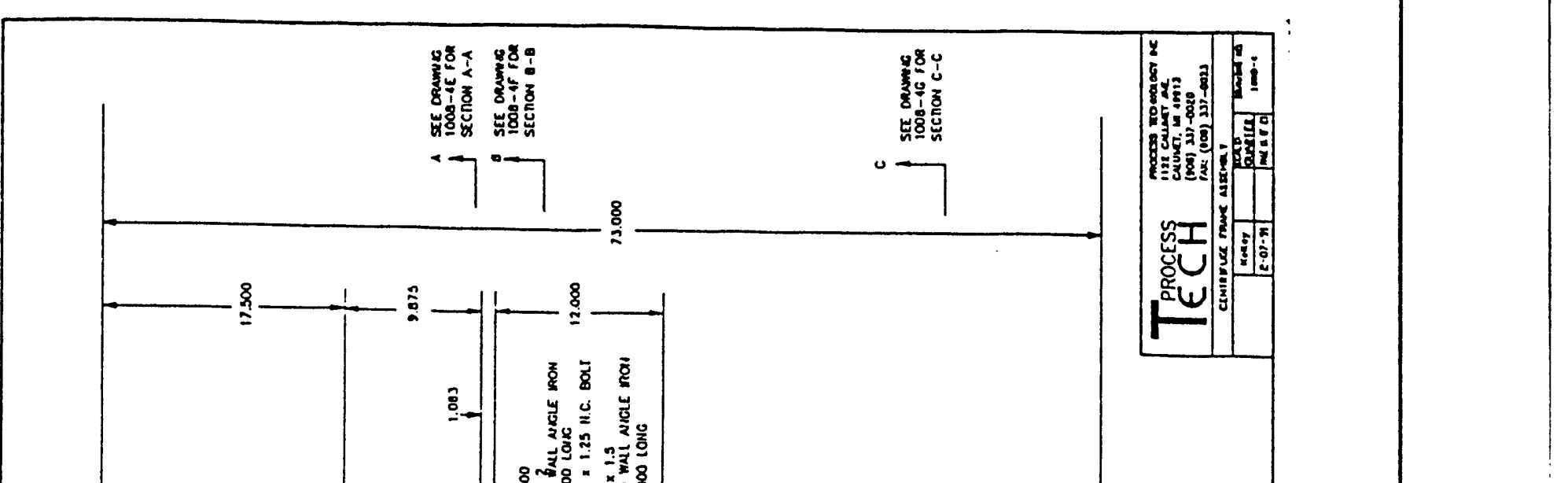


contract include the following: Biweekly, Quality Assurance/Quality Control Plan, Coal Procurement and Characterization Plan, Washability Analyses Report, Separating Media Evaluation Plan, Separating Media Test Plan, Process optimization Test Plan, Preliminary Separating Media Evaluation Report, and Final Separating Media Evaluation and Test Report.

Activity: The biweekly reports have kept DOE up to date with progress of the project. Other reports and plans are mentioned elsewhere in this report.

\section{Task 8 - Conceptual Design}

Task Description or objective(s): This task is performed with the objective of providing DOE with conceptual description and detailed estimate of cost to construct and operate a poc-scale advanced cycloning test module. ICF Kaiser Engineers will be the lead team member for Task 8 . This task involves the conceptual design of a fully integrated, continuous-operation, proof-of-concept (POC) scale advanced cycloning test module. The conceptual design will be sized for 3 tons per hour feed rate and will include all necessary pre-treatment, cleaning and post-treatment unit operations. The conceptual design will be based on the results of the Process optimization tests performed under Phase III of Task 6.

Activity: No activity scheduled during this period.

\section{Task 9 - Final Reporting}

Task Description or objective(s): The project team members will submit a Draft Final Technical Report at the conclusion of the 28 th month of the project. This report will be preceded by a detailed outline to be commented on by the DOE. The final report will meet contract requirements as stated in the Project Work Plan and will comply with DOE Order 1332.1A (Uniform Reporting system).

Activity: No activity scheduled during this period.

\section{Task 10 - Decommissioning}

Task Description or objective(s): CTC shall be responsible for decommissioning, protecting, removing, and disposing of all contractor installed property encompassed by the contract. Contractor procured Government property shall be protected and dispositioned as directed by the DOE CO. This is strictly limited to the cost of decommissioning, removal, protection, and shipment from CTC to PETC.

Activity: No activity scheduled during this period. 
APPENDIX A

Washability of Illinois No. 6 


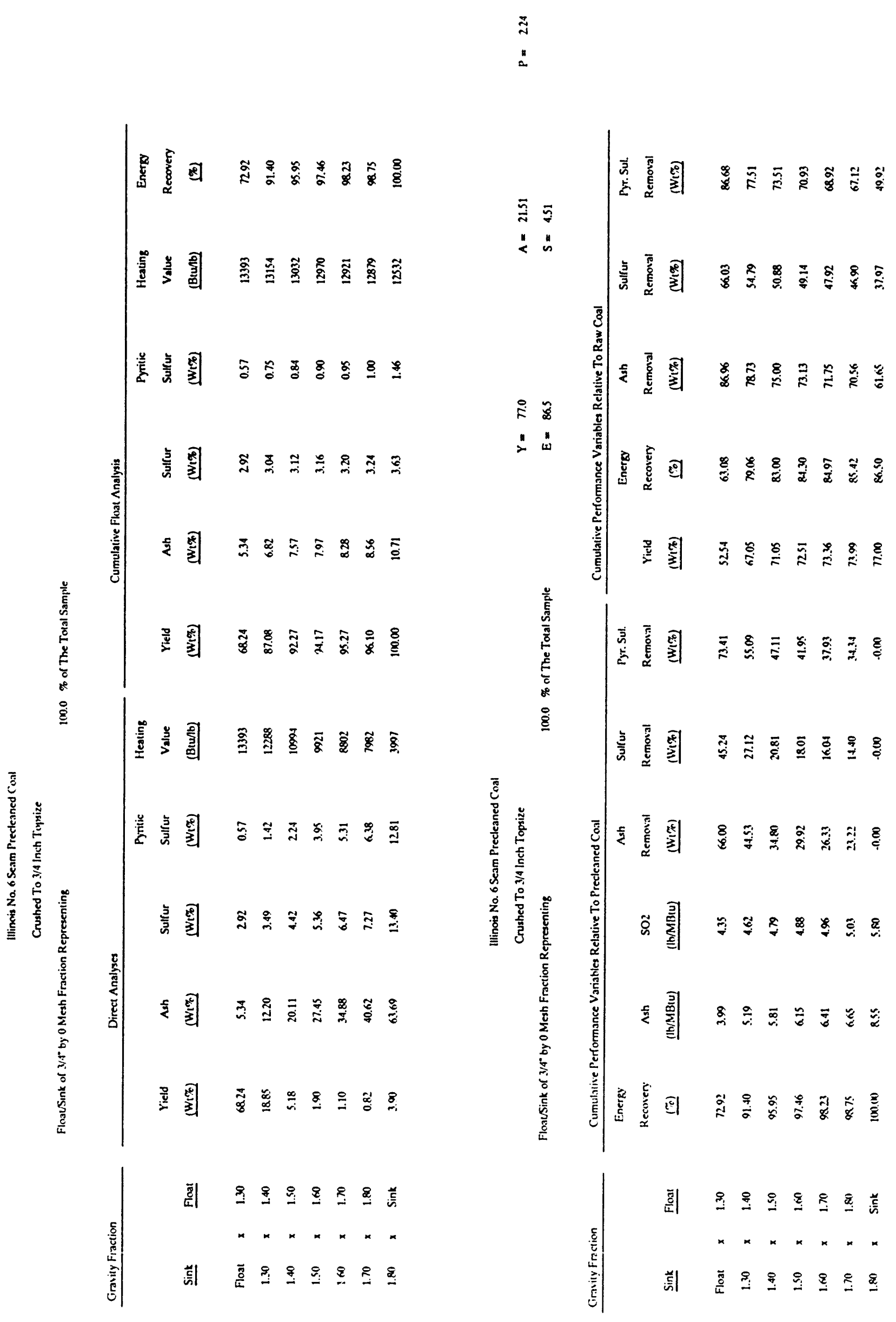




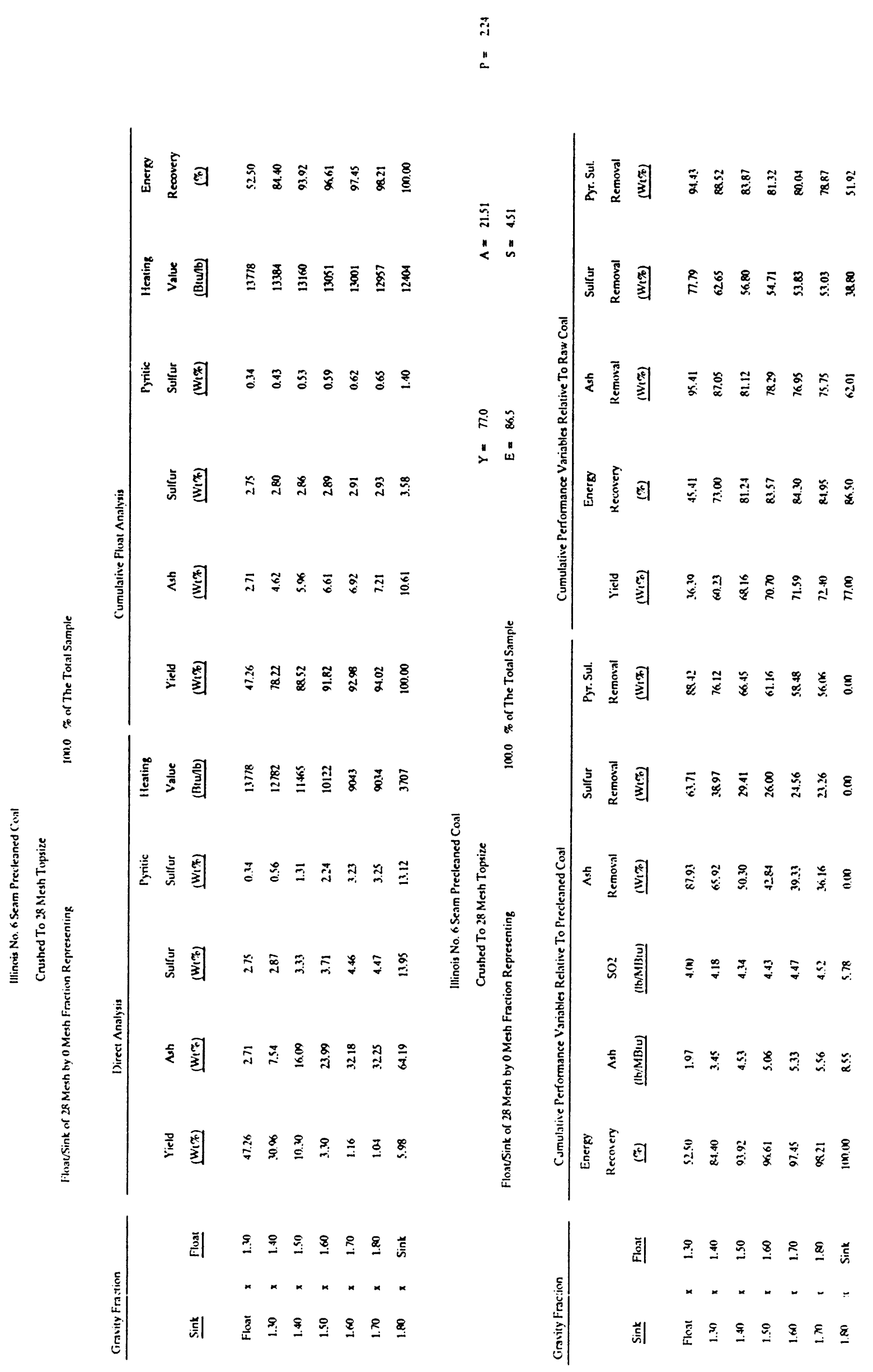




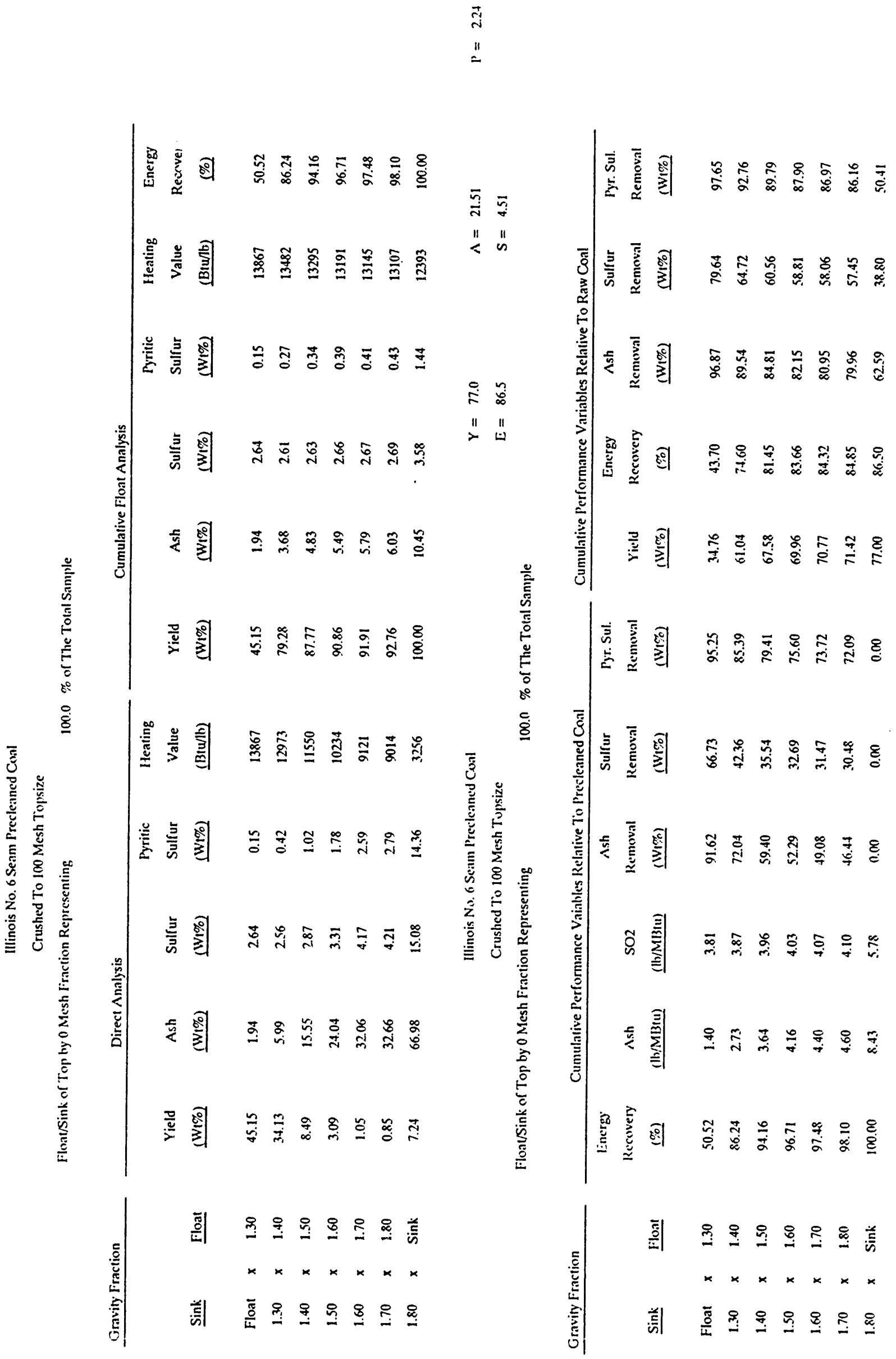




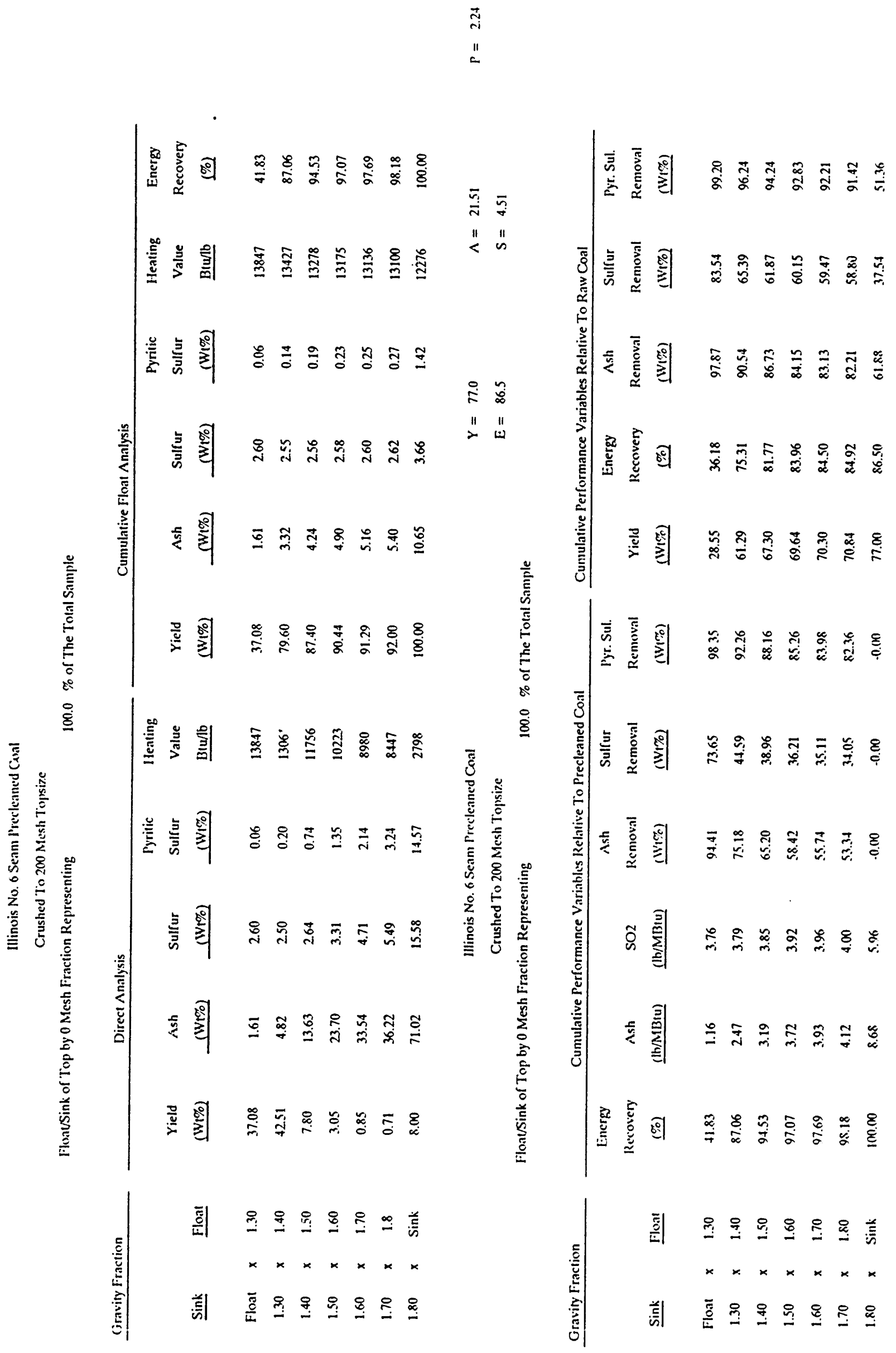


$\vec{\pi}$

"I

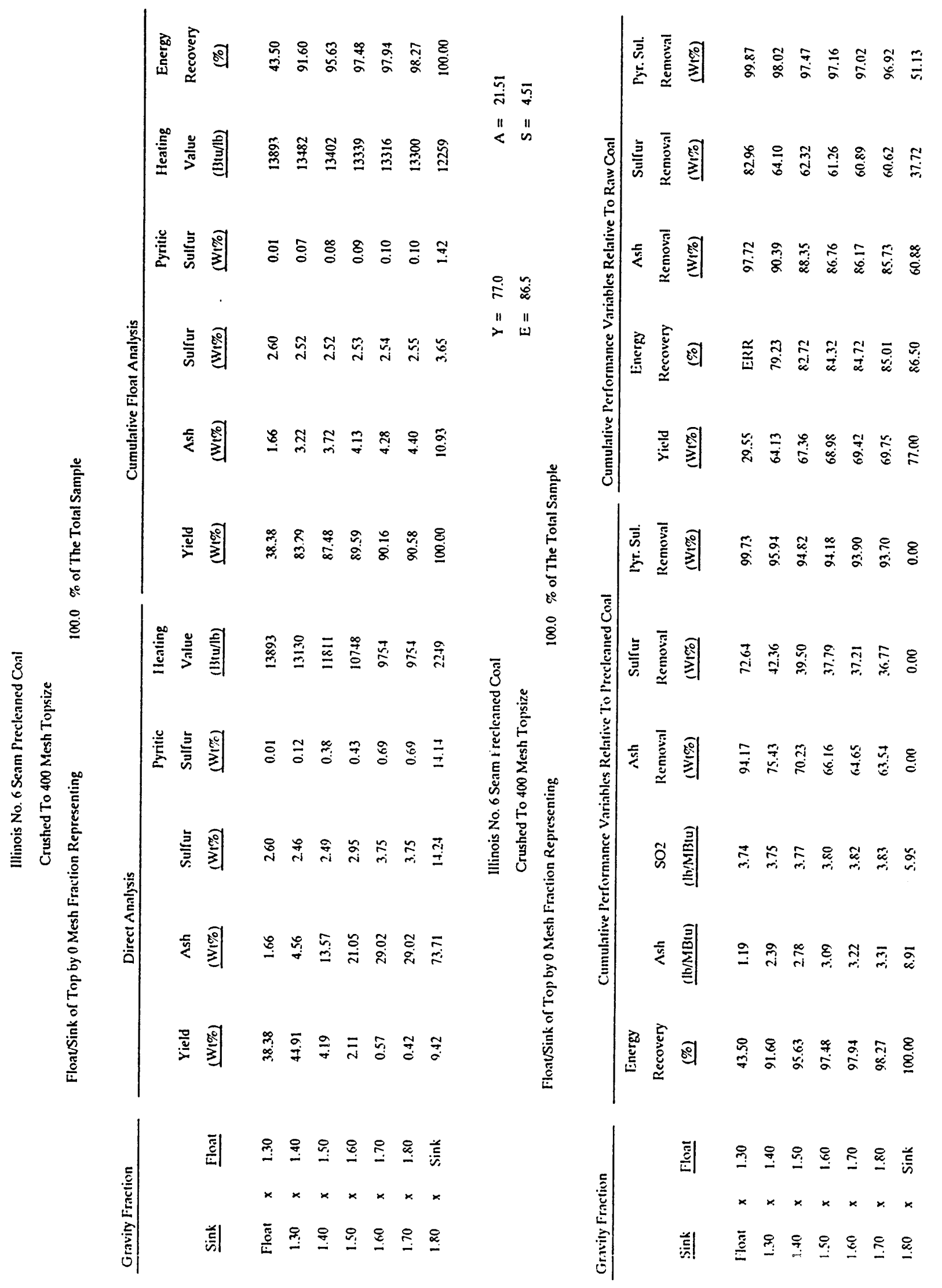




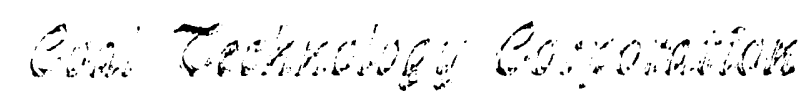

103 Thomas Road

Bristol, VA 24201

November 6, 1991
Tel. (703) 669-6515

Jax (703) 669-2161

Mr. William P. Earnett

Contracting officer's Representative

U. S. Department of Energy

Pittsburgh Energy Technology Center

P. O. Box 10940

Pittsburgh, Pennsylvania 15236

Dear Mr. Barnett:

Re: DOE Contract \#DE-AC22-90PC90177,

"Evaluation, Engineering and Development

of Advanced Cyclone Processes"

Please find enclosed two copies of the revised Quarterly Technical progress Report \#04 for the period July 1 to september 30, 1991. I trust I have addressed your revisions adequately.

TD: mas

Sincerely yours, ,

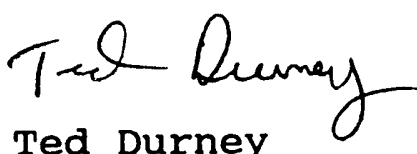

Ted Durney

Project Manager

Enclosures

CC: U. S. Department of Energy

Ms. MaryAnn Lundgren (1), Ms. Marilyn Keane (1), Mr. Bruce Utz (1), Mr. Richard Hucko (1), Office of Patent Counsel (1), DOE MS 58-M210 (3),

Mr. Randolph Pennington (1)

Dr. R. Wolfe (1), Mr. K. Grindstaff (1), Mr. C. Im (1),

Mr. P. Suardini, PTI (1), Mr. D. Ferris, ICF KE (1),

Mr. A. Devernoe, IGC (1), Dr. J. Hwang, MTU (1) 

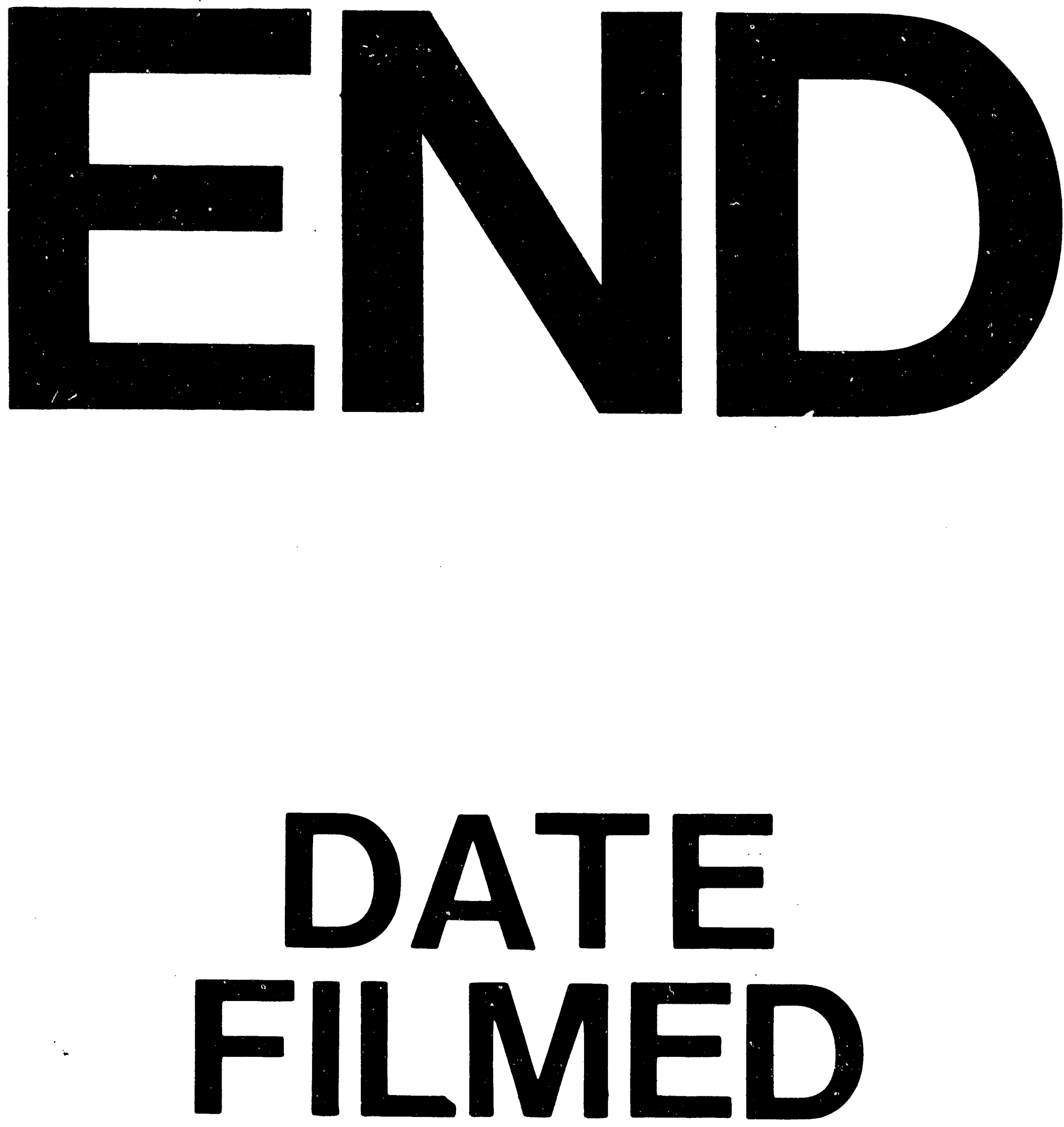

1
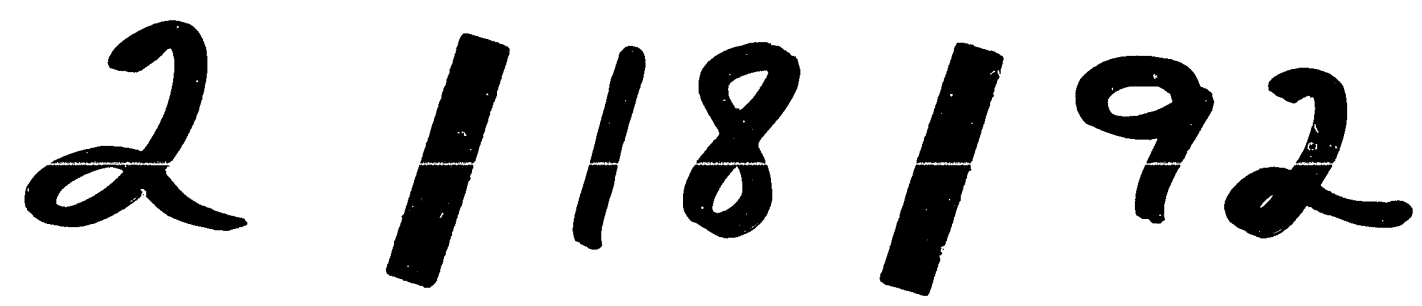
